(44) A. J. Deutsch, Publ. Astr. Soc. Pacif. 66, 58, I954.

(45) O. Struve, $A p . J .117$, I, I953.

(46) K. O. Wright, Mon. Not. R. Astr. Soc. I13, 338, 1953.

(47) A. McKellar et al., Nature, Lond., 169, 990, 1952.

(48) Su-Shu Huang and O. Struve, $A p . J$. 116, 410, 1952; 118, 463, 1953; Ann. Astrophys. 17, 85, 1954; $A p . J$. 121, 84, I955.

(49a) A. Slettebak, $A p . J$. I19, I46, I954.

(49b) A. Slettebak and R. F. Howard, $A p . J$. 121, 102, 1955.

(5o) A. Slettebak, $A p . J$. (in the Press).

(5I) J. B. Oke and J. L. Greenstein, $A p . J$. 120, 384, I954.

(52) E. Vitense, $Z, A p \cdot$ 32, r $35,1952$.

(53) E. Böhm-Vitense, $Z$. Ap. 34, 209, 1954.

(54) K. H. Böhm, $Z$. Ap. 34, 182, 1954.

(55) K. H. Böhm, $Z$. Ap. 35, I79, 1954.

(56) V. V. Sobolev, Astr. J. U.S.S.R. 28, 5, I95I.

(57) V. V. Sobolev, Astr. J. U.S.S.R. 3I, 3, 1954.

(58) S. G. Sliusarev, C.R. Acad. Sci. U.S.S.R. 95, no. 4, 1954.

(59) A. B. Underhill and J. K. MacDonald, $A p . J$. II5, 577, I952.

(60) A. B. Underhill, $A p . J$. I16, 446, I952.

(6I) O. A. Melnikov, Astr. J. U.S.S.R. 31, 259, I954.

(62) See Conference on Stellar Atmospheres, I954, ed. Wrubel (Bloomington, Indiana).

(63) G. Jurgens, Z. Phys. r34, 21, I952.

(64) J. E. Milligan and L. H. Aller, Astr. J. 58, 45, I953.

(65) A. A. Nikitin, Leningrad Univ. Bull. no. 6, 1952.

(66) A. A. Nikitin, Astr. J. U.S.S.R. 29, no. 4, 1952.

(67) A. A. Nikitin, C.R. Acad. Sci. U.S.S.R. 85, no. 2, 1952.

(68) A. A. Nikitin, Ann. Len. Univ. no. I 53 (issue 25), 1952; C.R. Acad. Sci. U.S.S.R. 84, no. 5, 1952.

(69) A. A. Nikitin, C.R. Acad. Sci. U.S.S.R. 98, no. I, I954 (and in the Press); Trans. Len. Univ. 1954 (in the Press).

(70) H. H. Voigt, $Z$. Ap. 31, 48, I952.

(7I) E. R. Mustel and L. S. Galkin, Publ. Crim. Obs. 12, 148, 1954.

(72) E. R. Mustel and L. S. Galkin, Publ. Crim. Obs. 13, 9, I955.

(73) A. A. Nikitin, in The Second Conference on Problems of Cosmogony (Acad. Sci., Moscow, U.S.S.R. 1953), pp. 453-65.

(74) F. Hoyle, $A p . J$. Suppl. I, no. 5, 1954.

(75) A. G. W. Cameron, $A p . J$. 121, I44, 955.

\title{
APPENDIX
}

\section{A SUGGESTION FOR CONSIDERATION BY COMMISSION 29}

\section{Classification of Stars of the Giant Branch, G 5 to $\mathrm{K}_{3}$}

The bands of $\mathrm{CN}$, particularly those with heads at $\lambda 3883$ and $\lambda 42 \mathrm{I} 5$, have long been known to show a positive luminosity effect and have been employed in the estimation of spectroscopic absolute magnitudes (I). More recently, however, it has been established that stars of a given spectral type and absolute magnitude show a real dispersion in the strength of their $\mathrm{CN}$ bands. This is not a random scatter, but is correlated with the space velocities of the stars in the sense that the percentage of stars with abnormally weak $\mathrm{CN}$ rises with increasing luminosity (2). Weak $\mathrm{CN}$ bands thus appear to be a characteristic of 'population II' stars, and extreme examples of the weakening are found among the members of globular clusters. On the other hand, a number of stars with unusually strong $\mathrm{CN}$ bands are also known, and these have sometimes been designated as ' $\lambda \mathrm{4I}^{\mathrm{I}} \mathrm{O}^{\text {' }}$ stars, though different observers have been somewhat inconsistent in using this last term (3). 
These discrepancies in $\mathrm{CN}$ intensity can be recognized on spectrograms having a scale of at least $\mathrm{I} 20 \AA \mathrm{m} / \mathrm{mm}$. in stars of types $\mathrm{G}_{5}$ to $\mathrm{K}_{3}$ and of luminosity classes IV to $\mathrm{I}$.* The visual estimates of $\mathrm{CN}$ strength are confirmed by photometric measurements of the break in the continuous spectrum at the $\lambda_{42} 15$ head. Consequently, it is possible to introduce additional physical information into catalogues of spectral types if the luminosity is estimated from atomic line criteria alone (by such ratios as 4077/4063, $4 \mathrm{I} 72 / 4 \mathrm{I} 85$, etc.), and any departure of the $\mathrm{CN}$ bands from normal is then indicated separately. It is suggested that the amount of the $\mathrm{CN}$ discrepancy be shown by the symbol ' $\mathrm{CN}$ ' followed by negative numbers running, say, from $-\mathrm{I}$ to -5 for stars having a deficiency of $\mathrm{CN}$. Corresponding positive numbers would measure $\mathrm{CN}$ bands stronger than normal. Examples of stars for which $\mathrm{CN}$ strength has been either estimated or measured photometrically at the Yerkes, Mount Wilson, or Perkins Observatory follow:

\begin{tabular}{|c|c|c|c|c|c|c|c|c|c|c|}
\hline \multicolumn{4}{|c|}{ Strong CN } & \multicolumn{3}{|c|}{ Normal CN } & \multicolumn{4}{|c|}{ Weak $\mathrm{CN}$} \\
\hline$\alpha$ Ser & $\mathrm{K} 2$ & III & $\mathrm{CN}+2$ & $\zeta$ Cyg & G8 & II & $\epsilon$ Dra & G8 & III & $\mathrm{CN}-\mathrm{I}$ \\
\hline $37 \mathrm{Lib}$ & $\mathrm{KI}$ & IV - & $\mathrm{CN}+\mathrm{I}$ & $\kappa$ Cyg & Ko & III & $\begin{array}{l}\delta \text { Boo } \\
48 \text { Her } \\
\text { HR 6I52 }\end{array}$ & $\begin{array}{l}\text { G8 } \\
\mathrm{K}_{\mathrm{I}} \\
\mathrm{G} 9\end{array}$ & $\begin{array}{l}\text { III + } \\
\text { II-III } \\
\text { II }\end{array}$ & $\begin{array}{l}\mathrm{CN}-1 \\
\mathrm{CN}-2 \\
\mathrm{CN}-3\end{array}$ \\
\hline
\end{tabular}

It is likely that stars having $\mathrm{CN}$ bands abnormally weak probably belong to the same physical group as the F $5-\mathrm{G} 8$ stars with unusually weak absorption lines of the metals. N. G. Roman (3) has suggested that the notation 'wk-l' be added to the type for the $F_{5-G} 5$ weak-line stars. For later types, she adds 'wk CN' for stars with conspicuous $\mathrm{CN}$ weakening, and again uses 'wk-l' for the less extreme cases and other stars which she considers physically related to these. The objection to the latter notation is that it often contradicts what the observer sees on spectrograms of moderate or small dispersion on stars of the later types ( $\mathrm{G} 8$ to $\mathrm{K}_{3}$ ), where general line weakening can rarely be noticed. Indeed, some lines $(\lambda \lambda 4 \mathrm{I} 43,4226$, etc.) may be slightly strengthened in population II stars. Consequently, I suggest that the term 'wk-l' should be used for classifiers only when they can clearly see weakening of several metallic lines.

When the numerical $\mathrm{CN}$ classification has been applied to a considerable number of stars it should be possible to judge better whether stars with a deficiency of CN really differ from average low-velocity stars of the solar neighbourhood in just one physical parameter. According to Schwarzschild, Spitzer and Wildt (4) such a variable parameter can be taken to be the ratio of hydrogen to all the heavier elements. An increase in this ratio would raise the opacity and weaken both the $\mathrm{CN}$ bands (considerably) and the atomic lines (slightly), while leaving the $\mathrm{CH}$ bands almost unchanged, in good agreement with the observations.

P. C. KeENAN

\section{REFERENCES}

(I) The pioneer application of the $\mathrm{CN}$ bands as luminosity criteria was by B. Lindblad, Ap. J. 55, 85, 1922 .

(2) Weakness of $\mathrm{CN}$ bands in the spectra of certain stars of high velocity was first detected by W. W. Morgan, An Atlas of Stellar Spectra (1943), Plate 45. Further evidence for the correlation with velocity has been given by Keenan and Keller, Ap. J. 1r7, 24I, I953, Table 4.

(3) N. G. Roman, $A p . J .116$, 122, 1952.

(4) M. Schwarzschild, L. Spitzer and R. Wildt, Ap.J. II4, 398, 1951.

* CN intensity can be estimated on plates of much smaller dispersion, but unless sufficient atomic lines can be resolved to permit independent estimation of the luminosity, the observer will have no way of knowing whether the observed CN strength is anomalous. 
No bright novae appeared during the last three years and the investigations of the spectra of novae were not numerous.

N Sco I952 (Haro), $9^{\mathrm{m}}$, N Sgr 1953 (Haro) Io $^{\mathrm{m}} \cdot 5$, N Sgr I954 (Wild) Iom were accessible for spectral studies by means of telescopes of medium power. Although special spectrograms of these stars were obtained, detailed investigations, or subsequent observations of them were apparently not made. In the meantime N Sgr r954 was unusual, since it showed the G-class spectrum (HAC $\mathrm{x} 27 \mathrm{I}$ ).

G. Larsson-Leander ( $\mathrm{x}$ ) carried out very detailed complex photometric, spectroscopic and spectrophotometric investigations of the nova DK Lac I950. Its absorption spectrum, based on numerous spectrograms, is now being investigated by $\mathrm{D}$. McLaughlin. R. Bartaya (2) completed the photometric and spectrophotometric investigation of $\mathrm{N}$ Ser I948, discovered by her, using objective prism spectrograms. The reduction of spectrograms of both stars, followed by conclusions as to the physical state of their envelopes, demonstrates that such novae of moderate apparent brightness can still be studied in detail. Thorough investigation of each nova is extremely important, not only for statistical comparison, but also because every nova possesses its own peculiarities.

$\eta$ Car, the slowest among the known novae, had a brightening in 1952, which was described on the basis of photometric observations by de Vaucouleurs and Eggen (3). In this connexion A. D. Thackeray (4) studied its spectrum in detail in the extremely wide range of $3700-8900 \AA$. Absorptions of $\mathrm{CaII}$ and of [FeII], displaced towards the violet, were observed.

The spectra of the old novae seem to have been studied more intensely. Thackeray (s) studied the spectrum of RR Tel. The continuous increase of ionization makes it possible to separate the forbidden lines of different ions, some of which were identified with [Fe IV] by Edlén, [ClIII], [Cliv], [AIII], [AIV] and [K IV]. Feast (6) analysed the more rapid variations in the spectrum of RR Pic I925. The results derived by Spencer Jones in his well-known monograph for the spectrum of this nova were confirmed by L. Gratton (unpublished) from a study of spectrograms secured in Argentina.

N Her I934 remained under observation in I950 by P. Swings and P. Jose ( )). They noticed the continuation of important changes in the spectrum of its envelope. M. Walker (8) has found, from photo-electric measurements, that N Her I934 is an eclipsing binary of extremely short period (4 hours). This throws quite a new light on the nature of novae and makes possible for the first time a reliable estimate of masses of novae. It will be recalled that some investigators suggested (E. Mustel, in particular) that the masses of novae are as large as several hundred solar masses and perhaps even greater. This demonstrates the great inportance of systematic photometric observations of the old novae, which were hitherto made by Steavenson (Mon. Not. R. Astr. Soc.), unfortunately on but rare occasions and only visually.

It is a satisfaction to state that the photometric survey of old former novae is in progress at Stockholm (Larsson-Leander) down to $17^{\mathrm{m}}$. However, this limiting magnitude is insufficient.

The spectrum of RT Ser was carefully studied by Grandjean (9) and the spectrophotometry of T CrB from I 946 to I952 was completed by M. Bloch and Mao-Lin (xo).

The spectra of the nova-like stars BF and CI Cyg and Z And were studied by L. H. Aller (II), who drew many astrophysical conclusions from them. BF and CI Cyg and AX Per were also studied by Mao-Lin and M. Bloch (12).

Spectroscopic investigations by L. Gratton were devoted to the extremely rapid $\mathrm{N}$ Pup I942, with the largest known amplitude. The radial velocities and nebular stage of the latter were discussed.

A discussion of spectrograms of novae previously obtained was also made by $B$. Vorontsov-Velyaminov (spectrophotometry of $\mathrm{N}$ Her before its 'dip') and especially by $\mathrm{D}$. McLaughlin. For this Nova he gave a new identification of absorptions belonging to different svstems (13). The interpretation of similar data concerning other novae is in 
progress at the Michigan University. McLaughlin (14) has found the red coronal line in the spectra of the rapid novae N Pup I942 and N Aql I9r8. It was suspected in five other novae. McLaughlin found a progressive decrease of excitation (i.e. of the temperature) in the atmospheres of $\mathrm{N} \mathrm{Aql} \mathrm{I9I8,} \mathrm{RS} \mathrm{Oph} \mathrm{and} \mathrm{T} \mathrm{CrB}$, when at minimum. For other stars the behaviour of temperature is less evident. He also made an attempt to interpret the contours of the emission bands of $\mathrm{N} \mathrm{Aql} \mathrm{rgr8} \mathrm{in} \mathrm{its} \mathrm{nebular} \mathrm{stage.}$

We can mention that theories of novae were developed by E. Schatzman (15) and by J. Kopylov(16), giving masses of envelopes of novae from their spectra.

A symposium devoted to the non-stable stars took place in Moscow on 26-29 October 1954. Many reports were concerned with the theories of the nova phenomenon. These reports will be published as a separate volume.

Of the less common photometric studies of novae the note by Ashbrook on $T$ Boo, FU Ori, CT Ser I948(Iy) and on the enigmatic nova in Her and on the possible nova $+43^{\circ} \mathrm{I}(\mathrm{I} 8)$ can be mentioned.

It is possible that our present report is not complete, since not all investigators have sent us their information and since not all publications were at our disposal.

Besides the activity reported above, the sub-commission on the spectra of novae began at last to compile the data on all existing spectrograms of novae. Up to the present time complete lists of spectrograms have been received from U.S.S.R. (except Crimean and Pulkovo), from England and the Dominions, from Argentina and from the Meudon Observatory.

Dr McLaughlin reports that the compilation of such data from U.S.A. is making good progress, but its large volume causes difficulties.

Neither were data received from Germany, Austria, Sweden, Italy, France (except Meudon), Japan, Victoria Observatory (Canada), Poland and Mexico.

\section{Recommendations}

It is the opinion of the president of the sub-commission that among the problems committed to that sub-commission should be included the photometric and theoretical investigations of novae, which are so closely related to the spectroscopic observations. In particular it is desirable that the brightness of all novae at minimum be determined when they are brighter than $20^{\mathrm{m}}-2 \mathrm{I}^{\mathrm{m}}$ and that radiometric observations of the appearing novae be begun.

\section{B. A. Vorontsov-Velyaminov} President of the Sub-commission

\section{Addenda to the report of the sub-commission on the spectra of novae}

Stratton recommends the study of supernovae spectra in the light of the spectra observed in high-velocity filaments in such radio sources as Tau A and Cas A.

Deutsch observed Wild's supernova (I954) in NGC 5668. The red shift of the system is $1600 \mathrm{~km}$./sec., permitting observation of the interstellar $\mathrm{H}$ and $\mathrm{K}$ lines in the gas of NGC 5668, separated from those in our own. The strengths of the lines were comparable, i.e. roughly the same amount of gas was traversed by the line of sight in both systems.

From Prof. Melnikov's (rg) report on research in the U.S.S.R.: Nova Ser 1948 has been followed from I948-52 at the Abastumani Observatory. Minin (20) discusses the change of electron temperature in stellar envelopes not in radiative equilibrium. Nova Her I934 was studied after its minimum. The temperature for the star was found to be $65,000^{\circ}$ and for the electron envelope $7000^{\circ}$. Sobolev has studied the expected temperature and brightness changes in a nova envelope. The model employed is an outburst, which is optically thick, but with $\tau$ decreasing with time. The theory explains in general the observed spectra and in particular those observed light curves where there is a delay in increase of brightness before maximum. Dolidze is undertaking spectrophotometric studies of the P Cyg and nova-like stars. Gradients, the Balmer decrements and Zanstra temperatures are derived.

Jesse L. Greenstein 


\section{REFERENCES}

(I) G. Larsson-Leander, Stockholms Obs. Ann. I7, no. 8; 18, nos. 3 and 4, 1954.

(2) R. Bartaya, Bull. Abastumani Obs. nos. I 5 and 17 , 1953.

(3) G. de Vaucouleurs and O. J. Eggen, Publ. Astr. Soc. Pacif. 64, r85, 1952.

(4) A. D. Thackeray, Observatory, 73, 256, 1953; Mon. Not. R. Astr. Soc. 113, $211,1953$.

(5) A. D. Thackeray, Observatory, 74, 90, 1954; Mon. Not. R. Astr. Soc. 113, 21 I, I953.

(6) M. W. Feast, Observatory, 73, 256, 1953.

(7) P. Swings and P. Jose, $A p . J$. 116, 229, 1952.

(8) M. Walker, Publ. Astr. Soc. Pacif. 66, 230, I954.

(9) J. Grandjean, Ann. Astrophys. 15, 7, 1952.

(10) M Bloch and T. Mao-Lin, Ann. Astrophys. 16, 73, 1953.

(I I) L. H. Aller, Publ. Astr. Soc. Pacif. 64, 229, I952; Publ. Victoria Obs. 9, no. II, 1954.

(12) T. Mao-Lin and M. Bloch, Ann. Astrophys. I7, 6, I954.

(13) D. McLaughlin, $A p . J$. I19, I24, 1954.

(14) D. McLaughlin, $A p . J$. 118, 27, 1953.

(15) E. Schatzman, Ann. Astrophys. 17, no. 107, 1954.

(16) J. Kopylov, Publ. Crim. Astrophys. Obs. ro, 200, 1952.

(I7) J. Ashbrook, Astr. J. 58, no. 6.

(18) J. Ashbrook, Publ. Astr. Soc. Pacif. no. 389, 1954.

(19) O. A. Melnikov, Bull. Abastumani Obs. no. 15, 1953.

(20) I. N. Minin, Astr. J. U.S.S.R. 29, no. 2, 1952.

\section{9b. SUB-COMMISSION ON THE SPECTRA OF VARIABLE STARS}

In the past few years our knowledge of variable stars has grown beyond the classification of light variations. Astrophysical studies, viewed in the light of the distribution and motion of variable stars of different types, have arranged many of them in a coherent physical pattern.

The results of this clarification are twofold. First, variable stars are seen as a physical problem rather than a geometrical one-and this applies to eclipsing stars as well as to intrinsic variables. Second, the subject has broadened; the study of variable stars draws on contiguous areas of astronomy and astrophysics, and its limits become increasingly hard to draw. A survey of the current problems of variable stars can no longer be confined to these objects themselves, still less to a limited group of them. The so-called intrinsic and explosive variables are not even coterminous; their provinces overlap. So do those of the intrinsic and extrinsic variables: VV Cephei is an eclipsing semi-regular variable; W Serpentis may even be an eclipsing cepheid; DQ Herculis seems to be an eclipsing nova.

Variable star astronomy has, in fact, passed the pioneering stage. A consolidation of the subject calls for a selective and concerted (though not necessarily collaborative) attack. The previous report ( $\mathrm{x}$ ) contained a number of recommendations, some of which can be reiterated in the present one. I shall take the opportunity of mentioning a number of problems that seem to call for solution at the present time, and to be soluble with present equipment. At the same time I shall quote the members of the commission, and others, who have responded to requests for summaries of their current work and plans.

An area of enquiry that has passed the pioneering stage should call for the formulation and solution of specific questions. Thorough study of a few well-chosen stars from many aspects is of more value than scattered information about a large number. On the other hand, there is urgent need for completeness, especially in the data on the motions of variable stars, for until material from the southern hemisphere is represented we are still 'flying on one wing'. 


\section{Short-period variables}

Until conparatively recently, the intrinsic variables with periods less than a day have been regarded as a group with small dispersion in physical properties. That this view must be reconsidered is emphasized by the problems of their placement in the colourluminosity arrays of globular clusters; by the difference of period frequency in our neighbourhood and in the vicinity of the galactic centre; by anomalous relationships between their periods, their spectra, and their velocity distribution; and by the discovery of such objects as SX Phoenicis, of very short period and low luminosity.

Spectra, spectral changes and velocity curves should be studied, with especial reference to stars of extreme properties. For example, RR Lyrae stars with asymmetric curves should be studied over a large range of period, from CY Aquarii, XX Cygni to such stars as XX Virginis, VZ Aquilae, and CE Herculis. Those with variable light curve and beat periods will be of especial importance. Those with light curves of type $c$, comparatively rare in the galactic field, present interesting problems, rendered difficult by their tendency to variability of period (as with RU Piscium and SX Ursae Majoris).

The group of stars that includes SX Phoenicis, AI Velorum, and probably many others still undiscovered, should be intensively studied. The group that includes $\delta$ Scuti and $\gamma$ Eridani is equally to be recommended.

\section{Work in progress}

A. J. Deutsch reports a programme of study of XX Virginis with coudé dispersion.

P. Th. Oosterhoff reports that 'Mr Westerhout took about 75 spectrograms of SX Phoenicis with the Radcliffe reflector at Pretoria, which are being measured for radial velocities'.

L. Gratton reports on the study of AI Velorum by Gratton and Lavagnino, of which an account (2) has been given in the Transactions.

Harlan Smith has completed a study of some of the brighter galactic variables with light curves of type $c$. Concurrent photo-electric and spectroscopic observations at Harvard have established that two at least of these stars are in fact eclipsing stars of W Ursae Majoris type, others, however, are genuine intrinsic variables.

\section{Cepheid variables}

This group, again, has been shown in recent years to be multiple. The cepheids proper, assigned to population $I$, have been separated from stars of like period that are more nearly associated with population II by the revision of the zero point of the periodluminosity curve, by the recognition of specific differences of light curve in globular clusters and in the galactic field, and by the observation of discontinuous velocity curves and spectral differences for the latter stars. This discovery, and the comparative brightness of many cepheids, might make the group an attractive subject, yet few investigators have reported work on them. In the preceding report, attention was called to the importance of observing the cepheids of population II (large $z$ co-ordinate) by Mrs Payne Gaposchkin, Kukarkin and Joy. The need for accurate light- and velocity-curves of characteristic normal cepheids was emphasized by Oosterhoff.

Important problems are: (I) Critical comparison of physical properties of cepheids in populations I and II with similar periods. The important work done by Sanford and Abt for $W$ Virginis should be repeated for other high-latitude cepheids, and detailed comparisons carried out for 'classical' cepheids of like period. This work should be extended to a comparison of the RV Tauri stars of shortest period, such as AC Herculis, with the cepheids of the longest period, such as RS Puppis, U Carinae, and $l$ Carinae. (2) With the building of more powerful spectroscopic equipment in the southern hemisphere, the brighter cepheids in the Magellanic Clouds should be studied spectroscopically and photo-electrically, with especial attention to the dispersion of the period-luminosity curve and its relation to spectrum and colour. The normal colours of cepheids, over as 
large a range of luminosity as possible, would be an important by-product. (3) Radial velocities should be determined for a number of southern cepheids, to fill the present gap in longitude. This work could be planned so as to yield also spectroscopic studies of the important southern cepheids such as RS Puppis, UU Muscae and WZ Carinae, as well as such anomalous cepheids as AH Velorum, GH Carinae and GI Carinae.

\section{Work in progress}

L. Gratton reports: 'Emission lines were observed in the spectrum of $\beta$ Doradus; observations have been obtained on $\kappa$ Pavonis and S. Muscae.'

Miss Jehoulet reports:

Last winter some new spectra of the carbon star RU Camelopardalis were obtained by the author with the 82-inch telescope of the McDonald Observatory. The spectrum of this type II cepheid is very complicated; almost every line is blended, even with high dispersion. The radial velocity curve is difficult to determine with precision for three main reasons; $(a)$ the amplitude is very small, about $20 \mathrm{~km}$. $/ \mathrm{sec}$.; $(b)$ the identification of the lines is rather uncertain, due to blending; $(c)$ the star is faint.

In order to determine a comparative radial velocity curve, a series of spectra is being measured with the Hartmann spectrocomparator. This method eliminates the need for line identifications.

Microphotometer tracings will be made in order to study the behaviour of the molecular bands, mainly $\mathrm{CH}$ and $\mathrm{CN}$, as a function of light variation. Such tracings might prove useful in discussing the question of the doubling of certain lines near or at maximum light.

Some of our spectrograms have been photometrically calibrated. A study of the dissociation equilibrium is planned.

A. J. Deutsch reports a projected study of the same star, RU Camelopardalis, with coudé dispersion. He also reports the plan to study the peculiar cepheid, TU Cassiopeiae. Study of this star, which has long been known to display marked seconciary variations, is also reported by Eggen and by Bidelman; the latter confirms spectroscopically Eggen's observation that some maxima are bluer than others. A study of a long series of scattered photographic observations at Harvard has convinced the writer that the light curve undergoes secondary variations, but continuous study with high precision would be required to determine whether the variations can be represented by a beat period. This star should be studied concurrently with photo-electric and spectroscopic methods.

\section{Red variables}

That great progress has recently been made in the physical understanding of the longperiod variables is attested by the reports of Merrill, McKellar and Odgers, Joy, and Fujita in Vol. 8 of the Transactions. These investigations of individual stars invite work on atmospheric motions and curves of growth for other long-period variables, and a search for Technetium in the spectra of other red stars. The semiregular red variables, many of which are of bright apparent magnitude, should be equally fruitful subjects for spectrophotometry and analysis. It is hard to define the limits of red variable stars; general studies of the spectra and distribution of all red stars are relevant to the subject, and red dwarfs with the associated flare stars fall within its province.

\section{Work in progress}

W. Bidelman reports on general study of carbon stars:

A general discussion of the carbon and S stars appeared in the Liege Mem. no. 3, 57, I954, and a more complete account of the carbon stars will appear in the Stratton volume.... I eventually would like to observe all of the carbon stars known. 
A number of studies of special stars are also reported.

A. D. Thackeray writes:

Spectra of southern Me and Se variables, especially those with large amplitude like S Indi, are being studied. Omicron Ceti is being observed each year near minimum (Feast, Observatory, 73, 254, 1953).

W. Bidelman reports as follows on long-period variables:

The presence of anomalously strong lines of the rare-earth elements in the spectrum of the $\mathrm{S}$ star $\mathrm{R}$ Andromedae is pointed out in $A p . J . \mathbf{r} 7,377,1953$. Evidence that the atmospheric structure of a carbon Mira-type star is similar to that of an M type Mira star is given in a discussion of the ultra-violet spectrum of U Cygni (Publ. Astr. Soc. Pacif. 64, 133, 1952). Bidelman and Ratcliffe reported on the discovery of self-reversal of the bright $\mathrm{H} \alpha$ line in the spectrum of $\mathrm{T}$ Centauri near maximum (Publ. Astr. Soc. Pacif. 66, 255, 1954).

We note that $R$ Andromedae is the star in whose spectrum Technetium was found by Merrill.

The red supergiant $U$ Lacertae, a semiregular variable, was noted by Bidelman to have bright [FeIr] lines, and thus resembles WY Gemi and WY Velorum; its spectrum is $\mathrm{M}_{4}$.

L. Gratton reports that study of the spectrum of the semiregular carbon star Y Pavonis is in progress.

W. P. Bidelman (3) reports that the peculiar supergiant variable, $\rho$ Cass shows double lines.

A. D. Thackeray reports the study of Proxima Centauri.

\section{$R$ Coronae Borealis stars}

This small but well-defined group of luminous stars, apparently hydrogen-deficient, and characterized by high-excitation lines of $\mathrm{N}$ and $\mathrm{O}$, as well as those of $\mathrm{C}$, has been likened to the slow novae (4).

Further spectroscopic and photometric studies would be of great value, and a close comparison should be made with the available spectra of slow novae. Attention is drawn to three ninth-magnitude $\mathrm{R}$ Coronae stars in the southern hemisphere: UW Centauri, S Apodis, and RS Telescopii.

\section{Work in progress}

L. Gratton reports: 'Extensive measurements of wave-lengths and identifications of lines in the spectrum of RY Sagittarii are being made by Lavagnino. This work is very near completion.'

\section{T Tauri and associated stars}

Recognition of the importance of 'T-associations' has emphasized the discovery and physical study of variable stars within nebulosity. Here we are still in the exploratory stage, and the accumulation of material is very much to be desired.

Work in progress

Gratton reports that a study of RU Lupi is in progress.

A. J. Deutsch plans 'the exploration, at coudé dispersion, of the spectra of late-type stars in the Orion nebula and especially the nebular variables'.

\section{Bright-line stars}

A field that borders on and overlaps the study of the spectra of variable stars is that of the stars whose spectra show bright lines. Here again we are in the exploratory stage. Bright-line stars of all spectral classes will be fruitful sources for students of peculiar variables; shell stars, potential and ex-novae, and symbiotic variables. 
The bright-line stars of early type have been extensively catalogued by Merrill and his associates, and an important extension of the work has been carried out by Bidelman in his 'Catalogue and Bibliography of Emission Line Stars of Types later than B', which is contained in the Astrophysical Journal, Suppl. 7. Bidelman writes that this catalogue 'contains I I 4 stars with bright hydrogen lines and 426 stars with bright $H$ and $K$, and 903 references to known spectroscopic data on these stars.... This catalogue gives a considerable number of new classifications of variable stars, based largely on McDonald spectrograms.'

\section{Work in progress}

Special stars: A. J. Deutsch reports that 'visual and spectroscopic observations have been made of Mira B at the I954 minimum of Mira A. The spectra indicate an ephemeral absorption shell around the star, and large changes in line strengths within a 24 -hour period.'

L. Gratton reports a study of the irregular variable AG Carinae, 'a very interesting object of the P Cygni type. Its spectrum varied from A ze to B 5 e (approximately) from I949-50 to I953. It would be interesting to know whether the magnitude changed as well (the radial velocity did). We suspect a small change in I952 or early I953. This star, and others of P Cygni type, are being studied by Miss H. Hartmann.' A. D. Thackeray also reports that AG Carinae is on his observing list. Gratton reports study of the P Cygni star MR Carinae.

A. D. Thackeray places S Doradus on his list of stars for special study. Mr Henry Smith, who studied this Magellanic star during his stay at the Boyden station, reports:

$S$ Doradus, previously described as a P Cygni star, has an unique spectrum. The outstanding features are narrow Balmer lines in emission with narrow violet absorption components, and very strong narrow absorption lines of CaII. It is likely that $\mathrm{S}$ Doradus belongs to the class of bright blue variables described by Hubble and Sandage $(A P . J .118,353,1952)$.

\section{Explosive variables}

The province of the explosive variables ranges over the supernovae, the novae, the recurrent novae, the $U$ Geminorum stars and probably the symbiotic variables. They also have affiliations with the shell stars and perhaps, as noted above, with the $\mathrm{R}$ Coronae Borealis stars. They can scarcely be excluded from a general report on the spectra of variable stars, even though a special section is also assigned to them.

Much of the material on these stars is necessarily collected as occasion arises. The fruits of previous study and good planning may be seen in the investigations of DK Lacertae by P. Wellmann and G. Larsson-Leander, which might furnish models for future attacks on ephemeral explosive phenomena.

\section{Work in progress}

Peculiar novae: L. Gratton writes:

Extensive investigations of $\eta$ Carinae and its relations with the surrounding stars and nebulae are being made. Gratton shows that the star is a member of the O-association in Carina. At maximum it must have been very bright (-13 or more) so that it is certainly not a nova. The general character of the spectrum and light variations do not suggest the inclusion of this star among supernovae either. Attention is drawn to the fact that such a peculiar star is found among the members of an $\mathrm{O}$-association, i.e. among young stars.

These findings, which are not in agreement with previous conclusions by other workers, should stimulate continued study of one of the most interesting of all stars.

A series of spectra of RR Telescopii, secured at the Boyden Station, show its development from a purely absorption spectrum to the stage at which it was described by Thackeray (5). They are being analysed by the writer. 
Henry Smith reports:

A spectrogram of the slow nova RR Telescopii made 23-24 June I953 shows the emission spectrum essentially unchanged from the appearance in 1952, described by Thackeray. However, a second underlying emission spectrum had developed in considerable strength, showing broad lines of HeII and Nirr. This new spectrum is identical to that of the typical WN star HD 50896 .

A. D. Thackeray reports the study of the complicated variable AE Aquarii.

L. H. Aller reports studies of the symbiotic variables CI Cygni, BF Cygni and $Z$ Andromedae, recently published in the Publications of the Dominion Astrophysical Observatory. He reports further on AG Pegasi:

Gordon Grant and I have carried out a spectrophotometric study of this star, based on slit spectrograms obtained with the 37-inch reflector and the Curtis Schmidt from I949 to 1954 . The excitation temperature gradually increased with time, but the colour temperature and electron temperature seemed to stay near $10,000^{\circ}$, although the Zanstra temperature was much higher.

A. D. Thackeray reports the discovery of a new symbiotic star, Mayall no. I29.

The recent suggestion, by $\mathbf{M}$. Walker, that $\mathrm{DQ}$ Herculis may be an eclipsing star re-emphasizes the importance of studying novae at minimum light. The investigation should not be confined to known novae, but should also embrace stars such as MacRae $+43^{\circ} \mathrm{x}(6)$, V Sag, EM Cyg ( 7 ) and even UX Ursae Majoris.

A. J. Deutsch reports:

Following Merle Walker's discovery of very rapid fluctuations in the brightness of $\mathrm{T}$ Coronae Borealis (Publ. Astr. Soc. Pacif. 66, 7r, 1954), low-dispersion spectra were obtained simultaneously with his photo-electric observations. These spectra indicate that the observed light variations cannot be attributed to changes in the strength of the Balmer emission lines and continuum.

\section{Magnetic variables}

A. J. Deutsch submits the following report:

I. The period of spectrum variation and/or magnetic variation is now known for $\mathrm{I}_{4}$ stars (Vistas in Astronomy, London, in the Press). All conform to the period-line-width relation (Trans. I.A.U. 8, 80I, I952), with the possible exception of 21 Comae. For this star, the published period (S. Provin, $A p . J .118,489,1953$ ) has not been confirmed by my plates, which indicate a period near two days, in agreement with the line widths. A new determination (S. Provin, $A$ P. J. I18, 281, I953; A. J. Deutsch, $A s t r . J \cdot 58,37$, I953) for the period of 56 Arietis has removed the single discrepancy that was noted in I950 (Trans. I.A.U. 8, 801, 1952).

2. Radial velocities from the unidentified variable lines in the spectrum variable HD I24224 change from $(\gamma-40) \mathrm{km}$./sec. a quarter cycle before maximum strength, to $(\gamma+40) \mathrm{km}$. $/ \mathrm{sec}$. a quarter cycle after maximum strength (Vistas in Astronomy). Velocities from the nonvariable lines of $\mathrm{H}$ and $\mathrm{MgII}$ are constant within the errors of measurement.

3. The results given above, plus others already cited, further support the oblique-rotator model for a magnetic star. Accordingly, the theory has been developed for the electromagnetic field of an idealized star rigidly rotating in vacuo (A. J. Deutsch, $A p . J$. , in the Press). The theory establishes the compatibility with the Maxwell equations of a magnetic field symmetric around a different axis from that of the rotation. For the space outside the star, the theory indicates a field in which the electric vector has, in general, an appreciable component along the magnetic vector. At sufficiently low densities of interstellar matter, the electric field can therefore accelerate ions to cosmic-ray energies. But it is improbable that the density can be low enough near a real magnetic star for these acceleration processes to occur.

4. The stars HD I706I 2 and $\alpha$ Piscium $A$ are both spectrum variables with periods near 2 days; $\alpha$ Piscium $B$ is a double-line spectroscopic binary of short period, in which both 
components are metallic-line stars. Visual pairs like $\gamma$ Piscium, comprising a peculiar A star and a metallic-line star, are surprisingly abundant, and undoubtedly of evolutionary significance.

Deutsch further reports work in progress or contemplated in the near future:

I. Spectrophotometry of about 150 absorption lines in the spectra of the magnetic-andspectrum variable HD I 25248 and the peculiar A star $\gamma$ Equulei. The tracings are on hand and partially measured. The results will give quantitative information on the phase relations between lines of different elements in the spectrum variable; curves of growth; and an indication of the effects of magnetic intensification of sensitive lines.

2. Continued observations of selected spectrum variables for period-determinations and for radial velocities in some cases.

\section{$\beta$ Canis Majoris stars}

Although no report of work on stars of this class has been received, attention should again be called to Struve's (8) recommendation of six stars suited to detailed photometric studies.

\section{Eclipsing stars}

The realization that eclipsing stars must be regarded as physical as well as geometrical problems renders them particularly apt subjects for concurrent photometric and spectroscopic studies. The rich harvest still to be reaped in the southern hemisphere will garner not only new determinations of stellar masses, but also valuable information concerning the physical condition of supergiant eclipsing systems.

\section{Work in progress}

A. D. Thackeray reports that work is being carried on for five of the most interesting of eclipsing systems: GG Car, AL Velorum, BL Telescopii, AR Pavonis and W Crucis. 'TiO absorption', he writes, 'has been detected at minima of the eclipsing variables BL Telescopii by Feast, and AR Pavonis by Thackeray. The latter object shows nebular emission lines throughout eclipse and supergiant $\mathrm{F}$ absorption during emergence from eclipse.'

L. Gratton reports that the W Ursae Majoris system TY Puppis is being studied.

\section{Miscellaneous}

Gratton reports: 'Miss $M$. Corvalán found that the spectrum and radial velocity of $T$ Carinae did not vary from I949 to I953; the magnitude was also constant. Almost certainly the star is not a variable.' A similar conclusion was reached by S. Gaposchkin (9) on the basis of the Harvard plates.

Cecilia Payne Gaposchinin

President of the Sub-commission

\section{Addenda to the report of the sub-commission on variable stars}

Work on some unusual eclipsing variables is reported by Cousins and Feast (10): The star BL Tel may be a supergiant eclipsing system, period 778 days, consisting of an $\mathrm{F} 8$ and supergiant $F$. At the other extreme a very interesting star UX UMa is the eclipsing star of shortest period, 4.7 hours, which has been studied by Herbig and Walker(rr). The primary is an $\mathrm{O}$ star with emission at $\mathrm{H} \beta, \lambda 4686$ and $\lambda 4640$ of $\mathrm{N}$ III. The light curve and spectra vary.

Dwarf intrinsic variables have been worked on intensively by Joy. He classifies the flaring stars into the following groups: SS Cyg stars, which he views as spectroscopic binaries of short periods, with flares lasting from minutes to hours, and spectral type 
range $\mathrm{G}$ to $\mathrm{KO}$; $\mathrm{T}$ Tau stars with flares lasting weeks or months which have the same spectral type range, but are presumably new stars in dust clouds; faint stars involved in dust and gas with flares of months or years, in later spectral type range $\mathrm{K}_{3}$ to $\mathrm{M}_{3}$; extremely low-luminosity large proper-motion stars, with flares of minutes or hours, spectral type $\mathrm{M}_{4}$ to $\mathrm{M}_{5} \cdot 5$, which are often fainter components of visual doubles. He has been working extensively on the star AE Aqu. This star is similar to SS Cyg having $20 \AA$ wide strong emission lines of $\mathrm{H}, \mathrm{He}$ and $\mathrm{Ca}$ II superposed on a dwarf dKo absorption spectrum. The radial velocities indicate a binary, one component being an emission $\mathrm{K}$ star, the other a hot star with a strong continuous spectrum and wide bright lines. The period is 0.7 days and both masses are about equal to that of the Sun. The hot star is an intermediate subdwarf with absolute magnitude near +7 . Joy and Greenstein are making a high-dispersion investigation of the spectra of the dwarf $\mathrm{K}$ star.

Mira Cet has been observed by Joy for radial velocity variation as correlated with light variation. There are small displacements between emission and absorption lines which correlate with excitation potential. Maximum positive velocity occurs near the time of maximum light and the highest point of the curve is apparently correlaied with maximum of luminosity. The maxima of velocity at different cycles show a range nearly as great as a variation in a single cycle. The evidence for a complete velocity cycle corresponding to volume pulsation of the star is not convincing. The intensity of the blue companion gives some support to the idea of a twelve to fourteen-year period of its variation. Feast (xz) at Radcliffe has also been observing a spectrum of Mira during the r952-53 minimum. At minimum the emission lines of the faint blue companion are observed. The emission lines of hydrogen have a displacement, and absorption components on the violet edge.

The star $\chi$ Cyg has been observed by Fujita (13). Lick plates gave equivalent widths of approximately 2I 5 atomic and molecular lines. The curve of growth obtained was from laboratory transition probabilities. The star has a large turbulent velocity and a small damping constant, characteristic feature of a supergiant. Abundances of some atoms and molecules were obtained from the curve of growth.

The theory of $\delta$ Cephei was studied by Hitotuyanagi and Inaba (14). Based on model stellar atmospheres, an interpretation of the temperature and electron pressure has been made completely from the continuous spectrum, using Stebbins' six-colour photometry and Canavaggia's Balmer discontinuity measures. The derived radius of the photosphere disagrees with that found from the radial-velocity curve. In addition, a re-analysis of Walraven's line intensities in $\delta$ Cep was based on laboratory $g f$-values. The results are close to those obtained by Walraven; the turbulence varied from $5 \mathrm{~km}$. $/ \mathrm{sec}$. at maximum to $8 \mathrm{~km} . / \mathrm{sec}$. at minimum.

Herbig (xs) reports the detailed study of the bright $H$ and $K$ lines in the cepheid S Sag during a short time on the rising branch of the light curve. These emissions are unsymmetrical and displaced shortward. A survey of a number of other bright cepheids led to the conclusion that temporary presence of such emission lines is characteristic of classical cepheids with periods between 5 and $\mathrm{I} 6$ days (16). The population II cepheids W Vir and RU Cam show $\mathrm{H}$ and $\mathrm{K}$ emission. Kraft is working on the star X Cyg, I6-day, population I cepheid for the same phenomena.

The spectrophotometry of RR Lyr, for gradients and Balmer discontinuity by Fringant ( $r$ ) leads to a colorimetric description of RR Lyr which separates it from normal stars. Algol and RZ Cas, eclipsing stars, have been studied and the limb darkening obtained from the spectrophotometric characteristics (18). G. C. de Strobel has found an increase of emission $\mathrm{K}$ at primary eclipse, suggesting that the secondary has a large emitting envelope. $\mathrm{U}$ Cep is now being observed. Dadaev(rg) studied the eclipsing variables Ao Cas and $\beta$ Lyr for a detailed model which permits estimate of the instability of their atmospheres and the corpuscular emission.

The study of population II cepheids and related stars has been carried out by Abt. The star W Vir, a population II typical object, has been studied from high-dispersion spectra and photo-electric observations. The radial velocity curve, as obtained by Sanford, 
is a discontinuous one. Just before each light maximum a set of lines gradually appears shifted shortward. An integration of the velocity curve indicates that the material producing these lines moves outward 35 million kilometres and then returns. It disappears about 0.2 phase after the next set of lines appears. Each new set of lines is preceded by a hydrogen emission phenomenon which originates deep in the atmosphere. At the times of double lines the new shortward components give excitation temperatures that are $700^{\circ}$ to $1000^{\circ}$ higher than for the longward components. The ionization and electron temperatures and densities decrease during expansion and increase during contraction.

Abt has also started observations of RV Tau stars, U Mon, R Scu, and AC Her. These stars show a discontinuity in the radial velocity curve at each light maximum. Times of deep light minima are times of large expansion of the reversing layer and the shallow minima occur during small expansions. The expansions occasionally are of the order of size as the mean stellar radius. Large changes, by factors of Io to Ioo, in line-strength at times of single lines can be explained by variable continuous opacity within the region of formation of the absorption lines. Abt is also working on two typical I- to 2-day cepheids: BL Her has a period of $\mathrm{I} \cdot 3$ days and a large range in light, colour and radial velocity. SU Cas has a period of $\mathrm{I} \cdot 95$ days and small range in light. $\mathrm{He}$ is also working on T Vul, FF Aql. These are representatives of the large-amplitude and small-amplitude cepheids at the same period. The purpose of this project is to find physical and luminosity differences with particular application to the dispersion possible in the period luminosity relation.

Jesse L. Greenstein

\section{REFERENCES}

(I) Trans. I.A.U. 8, 43I, I952.

(2) L. Gratton, Trans, I.A.U. 8, 819, 1952.

(3) W. P. Bidelman, Astr. J. 57, 203, 1952; 58, 278, 1953; see also W. R. Beardsley, Astr. $J \cdot$ 58, 34, I953.

(4) W. P. Bidelman, Trans. I.A.U. 8, 852, 1952.

(5) A. D. Thackeray, Mon. Not. R. Astr. Soc. 113, no. 2, 1953.

(6) M. Walker, Publ. Astr. Soc. Pacif. 66, 7x, I954; J. L. Greenstein, Publ. Astr. Soc. Pacif. 66, 79, 1954 .

(7) E. M. and G. R. Burbidge, Ap.J. 118, 349, 1953.

(8) O. Struve, Trans. I.A.U. 8, 432.

(9) S. Gaposchkin, Ann. Harv. Coll. Obs. II5, 6r.

(10) A. W. J. Cousins and M. W. Feast, Observatory, 74, 88, 1954.

(II) G. H. Herbig and M. Walker, $A p . J$. 120, 278, 1954.

(I2) M. W. Feast, Observatory, 73, 254, 1953.

(r3) X. Fujita, Publ. Astr. Soc. Japan, 4, 81, I952.

(14) J. Hitotuyanagi and H. Inaba, Sci. Rep., Tohoku Univ. 36, 213, 322, 1952.

(I5) G. H. Herbig, $A p . J$. 116, 369, 1952.

(16) G. H. Herbig, Publ. Astr. Soc. Pacif. 64, 302, 1952.

(I7) A. M. Fringant, Publ. Inst. Astrophys. Paris, (A), no. I49.

(18) A. M. Fringant, Publ. Inst. Astrophys. Paris, (A), no. I67.

(19) A. N. Dadaev, Pulkovo Bull. no. 152, 31,' 1954. 


\section{9c. SOUS-COMMISSION DES BANDES MOLÉCULAIRES DANS LES}

\section{SPECTRES STELLAIRES}

Depuis le Congrès de Rome, la sous-commission a perdu deux de ses membres les plus distingués, le Père Gatterer, S.J., de la Specola Vaticana, et Mademoiselle (Dr) V. Gaze, de l'Observatoire de Crimée. Le Père Junkes, S.J., a bien voulu assumer la continuation de l'Atlas de Spectres Moléculaires, commencé par le Père Gatterer et a remplacé notre regretté Collègue au sein de la sous-commission.

\section{Développements relatifs aux résolutions de Zurich (I948), durant la période I952-54}

Les deux résolutions de 1948 concernaient:

(a) la compilation de tables de constantes des molécules d'intérêt astrophysique;

(b) la préparation d'un atlas de spectres de bandes importantes en astrophysique.

Un rapport couvrant la période I948-5I est reproduit dans le volume 8 des Transactions of the I.A.U. Depuis lors, d'importants progrès ont été accomplis.

\section{Compilation de constantes moléculaires}

Les deux volumes édités par Dr B. Rosen: Données spectroscopiques concernant les molécules diatomiques (Tables de constantes, no. 4) et Atlas des longueurs d'onde caractéristiques des bandes d'émission et d'absorption des molécules diatomiques (Tables de constantes, no. 5) sont parus chez Hermann et Cie, Paris.

Il paraît aussi opportun de signaler, ici, les rapports et enquêtes de la Commission Mixte de Spectroscopie (J. Opt. Soc. Amer. 4r, I53, I95I ; 43, 427, 1953). En particulier, les enquêtes de la sous-commission $h$ pour l'échange des problèmes de recherche ont orienté plusieurs physiciens vers l'étude en laboratoire de spectres moléculaires d'intérêt astronomique. Comme exemple, nous pouvons citer le nouveau laboratoire spectroscopique installé par le Professeur J. Genard à l'Université de la Sarre, dans le but principal d'étudier ou compléter des spectres importants pour les astrophysiciens. Une première étude détaillée du spectre du cyanogène-basée, en grande partie, sur des clichés prêtés par Dr C. C. Kiess--vient d'être publiée par Dr Weinard. D'autres laboratoires ont annoncé leur intention de procéder de même.

\section{Atlas photographique de spectres de bandes}

Le Père Junkes, S.J., nous a envoyé le rapport suivant:

REPORT ON THE PROJECT OF AN ATLAS OF BAND SPECTRA OF ASTROPHYSICAL INTEREST

With the premature death of Fr. Gatterer, the work on this project has undergone a temporary setback. His successors (Fr. Junkes and Fr. Salpeter) required time to get familiar with the special method of the Carbon Flame; then an exposure meter was developed (cf. Ricerche Spettroscopiche, Vol. II, fasc. 2) by Fr. Salpeter and Mr W. Bitterlich, Innsbruck, to prevent too much waste of the precious material, especially that of the rare earths, which have been kindly put at our disposal for this purpose, on a loan agreement, by the Ames Laboratory through the kind intervention of Dr Spedding.

\section{The Plan}

The original plan of 1950, as outlined by Fr. Gatterer to Dr A. McKellar and published in Trans. I.A.U. Vol. 8, p. 426, had to be changed a little. Every effort was made by Fr. Gatterer to get ready a first volume for the next meeting of the I.A.U., and this volume was intended to include the band spectra of the diatomic oxides of the metals which could be excited in the carbon flame. But experience showed that some of the metals which have very bright oxide bands in the arc, have none in the carbon flame. Hence, to avoid incompleteness of the series, it was decided to enclose also oxide spectra in the arc. Moreover, as the carbon 
flame does not reach the ultra-violet, these spectra, eventually, should also be completed by spectra in the arc. Hence the programme for the first volume became very comprehensive.

No fixed plans have been made, as yet, for the next volumes, especially in view of the fact that there will be much greater difficulties in getting suitable spectra in our Laboratory.

\section{The Present State of the Work}

(a) The spectra. Up to his last illness, Fr. Gatterer worked to get the spectrograms for this volume with the carbon flame. The band spectra of about thirteen oxides have been secured in this way, namely those of the oxides of $\mathrm{Ba}, \mathrm{Ca}, \mathrm{Ce}, \mathrm{Cr}, \mathrm{Dy}, \mathrm{La}, \mathrm{Nd}, \mathrm{Pr}, \mathrm{Sm}, \mathrm{Sr}$, $\mathrm{Ti}, \mathrm{V}, \mathrm{Y}$, to which those of $\mathrm{Fe}$ and $\mathrm{Mn}$ have been added by Fr. Salpeter. In the next months we hope to secure oxide spectra of $\mathrm{Sc}, \mathrm{Er}, \mathrm{Eu}, \mathrm{Gd}, \mathrm{Ho}, \mathrm{Lu}, \mathrm{Tb}, \mathrm{Tm}, \mathrm{Yb}$, with the carbon flame method, and the other ones with arc excitation, as $\mathrm{Ag}, \mathrm{Al}, \mathrm{B}, \mathrm{Be}, \mathrm{Mg}, \mathrm{Nb}, \mathrm{Pb}$, and some others, if they give suitable spectra.

(b) The measurements of the bands and the analysis of unknown spectra have been undertaken by Dr Rosen and his associates at the Liège Institut d'Astrophysique. There is hope that most of the needed wave-lengths will be at hand when the tables are being prepared for publication.

(c) The enlargement of the spectra will be made as outlined by Fr. Gatterer, to give a dispersion on the reproductions of $2 \AA / \mathrm{mm}$.

\section{The Prospects}

We hope to get the spectra available for enlargement by spring 1955, and the whole volume ready for publication at the end of 1955 , though we are aiming at finishing it earlier.

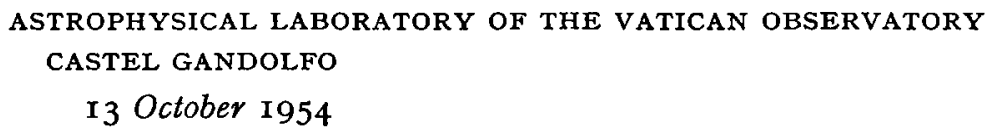

JOSEPH JUNKES, S.J. Director

D'autre part, Mr Rosen nous a annoncé (ro Nov. I954) que les spectrogrammes de $\mathrm{AlO}, \mathrm{BaO}, \mathrm{CaO}, \mathrm{CrO}, \mathrm{CeO}, \mathrm{FeO}, \mathrm{LaO}, \mathrm{PrO}, \mathrm{SrO}, \mathrm{TiO}$ et VO reçus du Père Junkes ont été étudiés à Liège et que les premiers résultats concernant ces spectres seront publiés au début de I955. La collaboration entre les laboratoires de spectroscopie du Vatican et de Liège a été efficace.

\section{Progrès dans le domaine des bandes moléculaires des spectres stellaires,}

\section{Observations} depuis le rapport antérieur

M. W. Feast, à l'Observatoire Radcliffe, a observé les spectres de nombreuses étoiles australes dont les bandes moléculaires, d'après le Catalogue $\mathrm{HD}$, semblaient présenter des anomalies. La plupart de ces étoiles ont pu être attribuées à l'une ou l'autre classe spectrale normale.

Un gros effort a porté sur l'étude des étoiles carbonées. Les travaux de P. Swings, A. McKellar et K. N. Rao 'extended knowledge of the spectra of late N-type stars into the ultra-violet, indicated the presence of new strong ultra-violet absorption bands, strengthened the identification of stellar bands with the $\lambda 4050$ group of $C_{3}$ and suggested a correlation between the occurrence of strong violet general opacity, of the 4050 bands and of the unidentified blue-green bands' (McKellar). D'autre part, McKellar et E. H. Richardson ont mesuré les gradients relatifs de dix étoiles carbonées froides de $\lambda 4800$ à $\lambda 3900$. "This allowed a quantitative evaluation of the drastic drop in intensity in the violet for certain late $\mathrm{N}$-type stars and a comparison with the intensity profiles of certain continua found in the laboratory, in particular one found by Phillips and Brewer and ascribed by them to the $\mathrm{C}_{3}$ molecule' (McKellar). 'Spectrograms of several cool carbon 
stars and also those of other spectral types for comparison, have been photographed with the three-prism Victoria spectrograph, dispersion at $\lambda$ roo0o being $133 \AA / \mathrm{mm}$. Over fifty absorption features were measured in the spectra of the carbon stars, the most outstanding ones being the heads of the 0,0 band of the red $C N$ system between about $\lambda$ r0870 and $\lambda$ II000' (McKellar). De plus, McKellar est, en ce moment, occupe à 'the study of the main $\mathrm{C}^{12} \mathrm{C}^{12}$ and isotopic $\mathrm{C}^{12} \mathrm{C}^{13}, \mathrm{C}^{13} \mathrm{C}^{13}$, Swan Bands of $\mathrm{C}_{2}$ in the spectra of 25 stars of type $\mathrm{N}$. There are a few rather puzzling facets to the results that require some consideration, but the actual reduction of tracings and similar work is almost completed' (McKellar).

Le même problème du rapport d'abondance $\mathrm{C}_{12}: \mathrm{C}_{13}$ est aussi étudié par Feast en ce qui concerne plusieurs étoiles australes $\mathrm{R}$ et $\mathrm{N}$. Celui-ci s'occupe également des 'peculiar stars AM Cen and GP Ori which show the strong ultra-violet opacity normally associated with the $\mathrm{N}$ stars but without any other strong molecular features. It has been suggested that the ultra-violet opacity is due to $\mathrm{NaH}$ (Liège Symposium, I954). The related star UY Cen has also been studied' (Feast).

J. D. Schopp a examiné, dans 28 géantes de type $\mathrm{G} 8-\mathrm{K}_{5}$, une raie de rotation due probablement à $\mathrm{C}_{13} \mathrm{~N}_{\mathbf{1 4}}$ (bande 0,0 ) et des raies de $\mathrm{C}_{12} \mathrm{~N}_{\mathbf{1 4}}$. Le rapport d'abondances $\mathrm{C}_{12}: \mathrm{C}_{13}$ est supérieur à 6,5 , c'est-à-dire à la valeur (4 ou 5 ) prédite pour de la matière résultant du cycle du carbone. Si le cycle du carbone a jamais opéré dans les intérieurs de ces géantes, il y a eu peu ou pas de mélange entre les intérieurs et les surfaces, au contraire de ce qui se passe pour la majorité des étoiles $\mathrm{R}$ et $\mathrm{N}$.

D'importants résultats sur les étoiles carbonées ont été obtenus par R. Bouigue, grâce à une étude spectrophotométrique d'une centaine d'étoiles $\mathrm{R}$ et $\mathrm{N}$ dans la région $\lambda \lambda{ }_{5400-}$ $6800 \AA$. Ses mesures ont porté surtout sur l'intensité des bandes de $C_{2}$, du système rouge de $\mathrm{CN}$ et des raies $\mathrm{D}$ de $\mathrm{Na}$. Elles ont permis de mettre en évidence une relation entre la croissance des raies $D$ et la variation de la température de vibration $T$. La température $\mathrm{T}$ et l'intensité de la raie $\mathrm{D}$ permettent de ranger les étoiles $\mathrm{R}$ et $\mathrm{N}$ d'une façon pratiquement identique à celle que $\mathrm{P}$. C. Keenan et W. W. Morgan ont proposée. Toutefois, les intensités de $\mathrm{C}_{2}$ et d'une bande centrée sur $6260 \AA$ et le développement de raies atomiques et de bandes moléculaires isotopiques conduisent à distinguer, entre $\mathrm{C}$ I et $\mathrm{C} 6$, deux sous-classes, distinctes de la subdivision en types $\mathrm{R}$ et $\mathrm{N}$.

J. G. Phillips a procédé à une importante étude des bandes de Swan de l'étoile R2, $\mathrm{HD}$ I82040, qui, selon Bidelman, est pauvre en hydrogène (faibles bandes de $\mathrm{CH}$ ).

Les températures de couleur $\left(5700^{\circ} \mathrm{K}\right.$, d'après Kron) ou vibrationnelle $\left(6200^{\circ} \mathrm{K}\right.$, d'après McKellar et Buscombe) paraissent trop élevées. En partant de la structure de rotation visible sur les clichés du Mt Wilson, Phillips trouve une température rotationnelle de $2300^{\circ} \mathrm{K}$. En se basant sur les intensités relatives des bandes de vibration de $\mathrm{C}_{2}$, Phillips trouve une température assez basse si les bandes utilisées sont voisines (p.ex. $1676^{\circ} \mathrm{K}$ en partant de $\mathrm{I}, 0$ et $2, \mathrm{I}$ ), plus élevée si les bandes sont bien séparées (p. ex. 4 IO $5^{\circ} \mathrm{K}$ en partant de I,O et $0, \mathrm{I}$ ). Un tel résultat s'explique si on suppose que l'opacité générale de l'atmosphère de l'étoile $\mathrm{R}$ augmente lorsqu'on va du rouge au bleu; un tel accroissement d'opacité pourrait être dû, soit à une source d'opacité continue dont le coefficient d'absorption varie avec la longueur d'onde, soit à un grand nombre de lignes d'absorption atomiques et moléculaires non résolues. Un résultat analogue avait été obtenu précédemment (P. Swings et A. S. King).

De nombreux spectres d'étoiles $\mathrm{N}$ obtenus à l'Observatoire d'Asiago sont actuellement étudiés par Mannino, Humblet et Swings. Leur examen porte sur les relations éventuelles entre le continuum violet, les bandes de Merrill-Sanford, le groupe de $C_{3}$, certaines raies atomiques et les bandes de Swan. Les relations avec les courbes de lumière sont examinées. Les mêmes auteurs tentent de déterminer le profil de l'absorption violette continue en partant de la réduction d'intensité des raies atomiques. Ils utilisent à cet effet des enregistrements de spectres pris au Mt Wilson (haute dispersion) et à Asiago (dispersion moyenne).

Le problème de l'opacité des étoiles $\mathrm{N}$, dans la région visuelle et infrarouge, est étudié à Tokyo par Y. Fujita, en partant de clichés coudés infrarouges du McDonald Observa- 
tory. Celui-ci procède aussi à l'étude détaillée des spectres de diverses étoiles carbonées, en continuation de son examen de U Cygni (I952).

Swings a signalé une possibilité de correspondance entre les bandes de Merrill-Sanford et les bandes ultraviolettes des étoiles $N$, d'une part, et certaines émissions non identifiées des comètes, d'autre part.

La classification des étoiles S a continué à faire l'objet des efforts de P. C. Keenan. Etant donné l'importance de cette question, les suggestions de Keenan sont reproduites in extenso:

In a paper now in the Press $(A p . J$.$) a revised classification, based on the intensities of the$ bands of $\mathrm{ZrO}$ and $\mathrm{LaO}$ as compared to those of $\mathrm{TiO}$, has been proposed for stars of type S. As a starting point for this scheme of classification it is taken as most desirable to use the strongest bands of these molecules because they are features which are observable even on slitless spectrograms of low dispersion. The classification attempts to take account of two physical parameters:

(a) Temperature, estimated from the sum of intensities, $\mathrm{TiO}+\mathrm{ZrO}$ (or $\mathrm{TiO}+\mathrm{LaO}$ ), since this sum appears to increase monotonically with decreasing temperature for S-type stars in general.

(b) Composition, estimated from the ratio of intensities, $\mathrm{ZrO} / \mathrm{TiO}$ (or $\mathrm{LaO} / \mathrm{TiO}$ ). This ratio probably reflects the differences in abundances of the heavy metals (fifth and sixth periods) as compared to the lighter metals of the third and fourth period.

The notation proposed gives the temperature class as the first figure following the letter $\mathrm{S}$, and the abundance class as the second figure. Thus $R$ Gem at maximum with type $S_{3,9 e}$ is classified as having higher temperature and relatively stronger $\mathrm{ZrO}$ than $\mathrm{HD} 6433^{2}$ with type S6,3. This notation is designed to merge smoothly into the accepted subclasses of type $M$ as the strength of the $\mathrm{ZrO}$ bands diminishes to the point where they are not noticeable on small-scale plates. Thus, for example, $\mathrm{S}_{5}, \mathrm{O}=\mathrm{M}_{5}$.

It is suggested that the usefulness of this scheme of classification can best be tested by observers working with various spectrographs having a range of dispersion as wide as possible.

The survey of S-type stars at the Perkins Observatory is being continued in order to make the catalogue of those brighter than the IIth visual magnitude as complete as possible. We should appreciate receiving information regarding any additional S-stars observed in this range of brightness.

Parmi les autres travaux sur les étoiles S, citons ceux de Feast, de Phillips et de Bidelman. Feast a étudié la magnitude absolue de l'étoile $S, \Pi^{1}$ Gruis; cette magnitude est importante pour une comparaison théorique de l'équilibre de dissociation dans les géantes et supergéantes. Phillips compare les structures vibrationnelies des bandes de ZrO dans $\mathrm{R}$ Geminorum et au laboratoire en vue de déterminer la température d'excitation des molécules ZrO dans l'atmosphère de cette étoile S. Quant à W. P. Bidelman, il a émis des suggestions fort intéressantes sur les relations entre étoiles $M, S$ et $C$.

La variation d'intensité des bandes de $\mathrm{CN}, \mathrm{C}_{2}$ et $\mathrm{CH}$ dans la variable de type $\mathrm{W}$ Vir, RU Camelopardalis, a suscité de nouvelles observations, mesures et discussions de Mlle D. Jehoulet.

Les bandes de $\mathrm{CN}$ ont aussi été photométrées dans de nombreuses étoiles $\mathrm{G}_{2}$ à $\mathrm{K}_{5}$ par P. C. Keenan:

Photographic photometry of the blue $\mathrm{CN}$ bands at ${ }_{42}{ }_{5} \AA$ is being carried out for a representative sample of stars of types $\mathrm{G}_{2}$ to $\mathrm{K}_{5}$. The available evidence indicates that the break in the continuum at $42 \mathrm{I}_{5} \AA$ is a reliable measure of $\mathrm{CN}$ strengths in spectra as late as $\mathrm{K}_{3}$, but for later types a correction for depression of the continuum by the wings of the $\mathrm{Ca}$ line at $4226 \AA$ must be applied. The present work should be regarded as only a preliminary survey, for it is very desirable that more accurate measurements of the $\mathrm{CN}$ break should be made by photo-electric spectrophotometry.

The data for G 8-K2 stars carefully classified on the MK system are being used to give:

(r) The real dispersion in $\mathrm{CN}$ intensity for stars having a particular temperature and luminosity.

(2) The correlation of $\mathrm{CN}$ strength with space motion of the star. 
Additional measurements on the infra-red bands near $7900 \AA$, which originate from the same lower electronic level of $\mathrm{CN}$, indicate that they do not decrease in intensity as rapidly as the blue bands in passing from type $K$ to type $M$. This may be evidence for changing relative opacity in the two spectral regions.

L. Gratton, dans sa comparaison spectrophotométrique entre les géantes $\mathrm{K}$ de grande et petite vitesse, a, comme on l'a fait précédemment dans des problèmes semblables, utilisé les bandes de $\mathrm{CH}$ et $\mathrm{CN}$.

Le problème de l'équilibre de dissociation moléculaire dans les étoiles froides a continué à faire l'objet de travaux théoriques. Swings a dirigé des travaux relatifs aux abondances de $\mathrm{C}_{3}$ et $\mathrm{C}_{4}$ dans les étoiles $\mathrm{R}$ et $\mathrm{N}$; l'accroissement de ces abondances lorsque la température décroit est beaucoup plus rapide que pour les molécules diatomiques telles que $C_{2}$. Philip Stanger a recommencé l'étude de l'équilibre moléculaire dans les atmosphères d'étoiles $S$, en partant des meilleures valeurs actuelles des chaleurs de dissociation, avec l'espoir de comprendre les variations de rapport des abondances de $\mathrm{ZrO}$ et TiO. Mais certaines des énergies de dissociation requises sont encore trop mal connues, p. ex. $\mathrm{ZrO}, \mathrm{LaO}, \mathrm{YO}, \mathrm{ScO}$ et $\mathrm{VO}$. R. Bouigue a aussi essayé d'interpréter ses observations en partant de la théorie de l'équilibre moléculaire. Il obtient, pour les étoiles $\mathrm{C}$, une abondance en carbone $\mathrm{C}^{12}$ à peine supérieure à l'abondance en oxygène, contrairement à ce que l'on pense habituellement. Si ce résultat est confirmé, le problème de la présence d'oxydes métalliques dans les atmosphères d'étoiles $C$ se poserait à nouveau.

Peut-être l'endroit est-il approprié pour mentionner le renouveau d'intérêt apporté au rôle possible des poussières (agglomérations de molécules) dans divers problèmes stellaires: variables à éclipses (Kopal), étoiles T Tauri (L. H. Aller et E. B. Weston), phénomènes sur Antarès (J. A. O'Keefe), R Coronae Borealis (Swings et collaborateurs), étoiles $\mathrm{N}$ (Rosen et Swings). Des exposés sur certaines de ces questions ont été publiés dans le volume du sixième (I954) Colloque International d'Astrophysique de Liège consacré aux Particules Solides dans les Astres. En particulier, O. Struve y a donné un exposé général du mécanisme de 'veiling' non sélectif et sélectif, reprenant, en les mettant à jour, les idées de R. Wildt, P. W. Merrill, J. A. O'Keefe et G. Herbig. Il a insisté sur l'intérêt spécial de l'effet des poussières dans les étoiles $T$ Tau et $\mathrm{R}$ CrB.

\section{Travaux de laboratoire}

Une sélection parmi les nombreux travaux sur des molécules d'intérêt astronomique est assez difficile. Nous avons choisi les recherches qui nous paraissent susceptibles d'applications dans un avenir rapproché. Il n'est d'ailleurs pas commode de séparer les molécules 'stellaires' de celles qui sont importantes dans des domaines connexes, tels que l'absorption interstellaire, les planètes et comètes, la haute atmosphère terrestre! Les travaux effectués à Liège par $\mathrm{B}$. Rosen et collaborateurs ont déjà été mentionnés à propos de l'atlas.

Le groupe 4050 est, à présent, définitivement attribué à la molécule $\mathrm{C}_{3}$ (A. E. Douglas); mais on ne connaît encore ni les constantes de cette molécule, ni le mécanisme exact de sa formation.

Le continuum violet des étoiles $\mathrm{N}$ semble bien avoir été reproduit en laboratoire par J. G. Phillips et Leo Brewer. Etant donné l'importance de ce problème, le rapport de J. G. Phillips est reproduit ci-dessous:

As is well known, the intensity of the ultra-violet continuum in the spectra of late N-type stars is much lower than predicted from the colour temperature of these stars. The emission deficiency starts at about $4500 \AA$, and continues as far to the violet as astronomical observations have been able to go. While several authors have suggested that the deficiency is produced by molecular absorptions, to the present time no known molecular system satisfies the astronomical requirements.

About a year ago, following the report that Garton in England had succeeded in producing the $4050 \AA$ (Swings) bands of $\mathrm{C}_{3}$ in the electric furnace, Dr Leo Brewer, of our Department of Chemistry, and I undertook the investigation of the ultra-violet region of the spectrum 
of carbon, using our electric furnace as the source, and scanning the spectrum photoelectrically. This scanning is accomplished by driving a scanning slit and IP 28 photomultiplier cell along the focal plane of a $5 \mathrm{~m}$. concave grating spectrograph. The output of the photocell is amplified and fed into a mechanical recorder. Using this apparatus, we succeeded in verifying the appearance of the $4050 \AA$ bands in emission, but we also found an extremely intense emission continuum. Only part of this continuum could be attributed to the scattering of furnace wall radiation into the spectrograph slit by dust in the furnace; the rest must be produced by emissions in the gas. After correcting for the scattered radiation, it was found that the gas emission continuum extended from about $4600 \AA$ to at least as far as $3700 \AA$; our observations did not extend beyond this latter wave-length. The continuum came in two peaks of intensity: one at $4300 \AA$ and another at $4000 \AA$. The peak at $4000 \AA$ was close to twice the intensity of the peak at $4300 \AA$.

As soon as we had discovered this new continuum, we realized that there was a good possibility that we had found the continuum responsible for the ultra-violet depression in the late N-type stars. This possibility was called to the attention of Dr McKellar during a visit that he made to Berkeley in January of this year, and he offered to undertake an investigation of this possibility, by comparing the intensity distributions in these late $\mathrm{N}$-type stars with the intensities in the same wave-length region in the spectra of certain earlier $\mathrm{N}$-type stars, which do not show the ultra-violet depression. The results of his investigation have been made available quite recently. His comparisons indicate that the absorption curves in the stellar spectra closely parallel the emission profiles we found in the laboratory; the peaks of absorption came at $4300 \AA$ and $4000 \AA$, with the $4000 \AA$ peak about twice the strength of the $4300 \AA$ peak. It was Dr McKellar's conclusion that there was good evidence to support the belief that we had found the correct molecular continuum.

A second problem, involving this new continuum, was the identification of the molecule responsible for its appearance. By various methods, we were able to show that only carbon atoms were included in the molecule. The number of these carbon atoms was determined by studying the variation of the intensity of the continuum, relative to the intensity of the Swan bands of $C_{2}$, as the carbon partial pressure in the electric furnace was varied at constant temperature. By invoking the law of mass action, we were able to show that the observed variation of intensity could only be explained by assuming that the carrier of the continuum was the $\mathrm{C}_{3}$ molecule.

Since the $C_{3}$ molecule thus appears to be responsible for both the Swings bands at $4050 \AA$ and the ultra-violet depression in the spectra of late $\mathrm{N}$-type stars, it becomes a very important molecule astrophysically. Indeed, the intensity of the ultra-violet cut-off suggests that the $\mathrm{C}_{3}$ abundance might be as great as the $\mathrm{C}_{2}$ abundance in the atmospheres of these objects, unless the transition probabilities are very different.

Nous avons signalé précédemment que Feast avait observé un continuum ultraviolet dans les étoiles $N$ ne présentant que des bandes carbonées très faibles. S'agit-il vraiment du même continuum que dans les 'véritables' étoiles $\mathrm{N}$ avancées, comme Y CVn? En tout cas, il est important de rapprocher cette observation de Feast du continuum observé par R. et L. Herman; celui-ci, probablement différent de celui de Phillips et Brewer, commence à $\lambda 4500$ et possède des maxima en $\lambda 4300$ et $\lambda 4000$. Le continuum de R. et L. Herman apparaît alors que le groupe $405^{\circ}$ est négligeable, les bandes de Swan faibles, mais les bandes de $\mathrm{CO}$ et $\mathrm{CH}$ sont présentes.

Au laboratoire du Prof. G. Herzberg, les spectres suivants ont été observés pour la première fois: BS (P. B. Zeeman), $\mathrm{NH}^{+}$et $\mathrm{CN}^{+}$(M. W. Feast; A. E. Douglas et P. M. Routly). Douglas et Routly ont obtenu 4 nouveaux systèmes de bandes de $C N$. En partant d'une étude du spectre de $\mathrm{N}_{2}{ }^{+}, \mathrm{A}$. E. Douglas a fourni un argument de plus pour la valeur 9.75 e.v. de $\mathrm{D}\left(\mathrm{N}_{2}\right)$. La valeur de $\mathrm{D}\left(\mathrm{O}_{2}\right)$ a été révisée $(5 \cdot$ II 5 e.v.) par P. A. Brix et $\mathrm{G}$. Herzberg. Les spectres d'absorption de $\mathrm{SH}$ et $\mathrm{SD}$ ont été étudiés à haute résolution par D. A. Ramsay. Les spectres d'absorption de $\mathrm{NH}_{2}$ et $\mathrm{HCO}$ ont été obtenus et étudiés par G. Herzberg et D. A. Ramsay. L'analyse vibrationnelle de AlC a été effectuée par P. B. Zeeman. 
Le président de la sous-commission désire exprimer sa profonde admiration pour l'œuvre accomplie par G. Herzberg.

J. G. Phillips a continué ses travaux de laboratoire sur les probabilités de transition des molécules d'intérêt astronomique qu'on peut produire dans le four de King.

Eventually, results will be obtained for the following molecules: (a) TiO, red system, and a comparison with the blue-green system; (b) $\mathrm{CN}$, red system, (c) $\mathrm{C}_{\mathbf{2}}$ Swan system; current work on the strengths of resolved rotational lines should make it possible to decide which of the various studies of this system which have appeared in the literature is the most nearly correct; $(d) \mathrm{ZrO}$, all three triplet systems; (e) $\mathrm{VO}, \mathrm{YO}, \mathrm{MgH}, \mathrm{CaH}$; preliminary results on most of these molecules have already been obtained, but they should be checked by more extensive studies.

P. C. Keenan et L. W. Schroeder ont pu attribuer les bandes non expliquées des étoiles $\mathrm{M}$ dans la région $\lambda \lambda 7400-8600$ à la molécule VO.

Le laboratoire de T. E. Nevin (Dublin) a fait preuve d'une belle activité dans le domaine de la sous-commission. Nevin et ses collaborateurs, notamment D. V. Stephens, ont développé les techniques d'excitation des hydrures de métaux, leur but étant d'étudier les hydrures de $\mathrm{Ti}$ à $\mathrm{Ni}$, notamment $\mathrm{Fe}$, un problème très important pour l'astrophysique. Nevin a obtenu de beaux spectres de $\mathrm{CrH}$ qui pourraient être mesurés si le besoin s'en fait sentir en astronomie, quoique l'analyse paraisse peu prometteuse. Il espère étudier bientôt $\mathrm{FeH}$. La comparaison détaillée des spectres de $\mathrm{MnH}$ et $\mathrm{MnD}$ a été récemment publiée; un nouveau système de $\mathrm{MnH}$ apparaît entre $\lambda 7200$ et $\lambda 8800$; des listes de longueurs d'onde de $\mathrm{MnH}$ peuvent être obtenues en s'adressant à Dr Nevin. W. Hayes a commencé une étude des composés halogénés de Mn (surtout la transition ${ }^{7} \Pi \rightarrow{ }^{7} \Sigma$ ). Il a étudié le domaine infrarouge photographique où il a découvert de nouveaux systèmes de $\mathrm{MnF}, \mathrm{MnCl}$ et $\mathrm{MnBr}$. Dans le bleu-vert, deux systèmes se superposent, dont $l^{\prime} u n$ est, sans doute, une transition ${ }^{5} \Pi \rightarrow{ }^{5} \Sigma$. D. Judge a examiné le spectre de $\mathrm{N}_{2}$ dans la région $8000-8500$ en utilisant différents types de décharge. Il a confirmé le nouveau système complexe (8260-8400) trouvé par P. K. Carroll et N. D. Sayers et découvert une nouvelle bande complexe de $\mathrm{N}_{2}$, dégradée vers le violet et avec tête en $\lambda 8202$; l'étude de cette bande exige l'analyse préalable des transitions $(5,4)$ et $(4,3)$ du premier système positif de $\mathrm{N}_{2}$ (Judge et Mackey).

Il est impossible de résumer toutes les publications sur les spectres moléculaires d'intérêt astronomique parues depuis I952. Parmi les travaux non encore cités, nous nous contenterons d'une liste d'exemples:*

$\mathrm{H}_{2}{ }^{+}$(théorie, A. Dalgarno, I954; D. R. Bates et al. I954);

AlH (B. Kleman, I953);

GeH (B. Kleman et E. A. Werhager, I953);

$\mathrm{C}^{13} \mathrm{O}^{16}$ (K. E. McCullok et G. Glockler, I953);

$\mathrm{CO}^{+}$(K. N. Rao et K. S. Sarma, I953);

NO (A. G. Gaydon et A. R. Fairbairn, I954);

$\mathrm{CaO}, \mathrm{MgO}$ (J. K. Patnaik, I952; A. Lagerqvist, I953 et I954);

$\mathrm{SrO}$ (G. Almqvist et A. Lagerqvist, I952; I. Kovacs et A. Budo, I952);

$\mathrm{ClO}$ (G. Porter et F. J. Wright, I952);

$\mathrm{BiO}$ (N. R. Bridge et H. G. Howell, I954);

$\mathrm{ZrO}, \mathrm{NbO}, \mathrm{AgO}$ (R. F. Barrow et U. Uhler, I953 et I954);

$\mathrm{O}_{2}$ (H. P. Broida et A. G. Gaydon, I954);

NbO (K. S. Rao, I952);

CS (P. J. Dyne et D. A. Ramsay, I952);

NS (R. F. Barrow et al. I954);

SiS (S. J. Q. Robinson et R. F. Barrow, I954);

$\mathrm{F}_{2}$ et fluorures alcalins (R. F. Barrow et A. D. Caunt, I953);

* Les références détaillées peuvent être fournies aux intéressés. 
AlF (H. C. Robinson et R. F. Barrow, I953; S. M. Naudé et T. J. Hugo, I953; P. G. Dodsworth et R. F. Barrow, I954);

$\mathrm{GaF}$ et InF (R. F. Barrow et al. I954);

$\mathrm{CCl}, \mathrm{SiCl}$ (R. F. Barrow et al. I954).

Quoiqu'on ne puisse pas encore considérer comme suffisant, l'effort consacré à la détermination théorique et, surtout, expérimentale des probabilités de transition absolues et relatives des bandes moléculaires, d'importants progrès ont été faits dans cette voie. Ils résultent notamment des travaux récents de:

J. G. Phillips (à Berkeley I954), voir ci-dessus;

R. Bouigue (à Toulouse, I954): calcul des probabilités pour $\mathrm{C}_{2}$ et $\mathrm{CN}$; mesures pour $\mathrm{CN}$ à partir d'un spectre de flamme;

Miss M. E. Pillow (à Londres, I952, I953, I954): calcul, surtout pour $\mathrm{C}_{2}, \mathrm{~N}_{2}, \mathrm{~N}_{2}{ }^{+}$ et $\mathrm{O}_{2}$;

A. A. Wyller (à Harvard, I952); calcul pour $\mathrm{C}_{2}$;

Ch. Manneback (à Louvain, 1952): calcul pour nombreuses molécules $\left(\mathrm{B}_{2}, \mathrm{BaH}\right.$, $\mathrm{BCl}, \mathrm{BeF}, \mathrm{BeH}, \mathrm{BF}, \mathrm{BN}, \mathrm{BO}, \mathrm{C}_{2}, \mathrm{CaH}, \mathrm{CH}, \mathrm{CH}^{+}, \mathrm{CN}, \mathrm{CO}, \mathrm{CO}^{+}, \mathrm{CS}, \mathrm{He}_{2}, \mathrm{InCl}$, InH, $\mathrm{MgH}, \mathrm{N}_{2}, \mathrm{~N}_{2}{ }^{+}, \mathrm{NO}, \mathrm{O}_{2}, \mathrm{O}_{2}{ }^{+}, \mathrm{OD}, \mathrm{OH}, \mathrm{OH}^{+}, \mathrm{SiN}, \mathrm{SiO}, \mathrm{SiS}, \mathrm{SnO}, \mathrm{SrH}$, $\mathrm{SrO}, \mathrm{TiO}, \mathrm{TlH}, \mathrm{VO}, \mathrm{ZnD}^{+}, \mathrm{ZnH}, \mathrm{ZnH}^{+}, \mathrm{ZrO}$ ).

du groupe de l'Université de Western Ontario, R. W. Nicholls, W. R. Jarmain, P. A. Fraser et autres (1952 à 1954): calculs (et mesures dans certains cas) pour molécules $\mathrm{N}_{2}, \mathrm{~N}_{2}{ }^{+}, \mathrm{CO}, \mathrm{CO}^{+}, \mathrm{CN}, \mathrm{OH}, \mathrm{NO}, \mathrm{O}_{2}, \mathrm{O}_{2}{ }^{+}$, TiO.

De nouvelles installations spectroscopiques à Ottawa, Berkeley, Vatican, Dublin, Sarrebruck, Liège, etc., qui sont déjà ou seront consacrées aux bandes moléculaires, laissent présager d'importants progrès dans un avenir rapproché. En particulier, un sérieux effort est fait dans l'ultraviolet lointain et l'infrarouge proche.

\section{Veux et sujets de discussion}

Etant donné la difficulté de séparer les molécules importantes pour les spectres stellaires et celles qui concernent les planètes, les comètes, l'atmosphère terrestre et la matière interstellaire, certaines des remarques qui suivent se rapporteront aussi à d'autres commissions. Nous nous sommes inspirés en partie de suggestions contenues dans la dernière enquête, encore inédite, du sous-comité $h$ (Exchange of Research Problems) de la Joint Commission for Spectroscopy. Remarquons encore que les suggestions de P. C. Keenan (no. I) et J. G. Phillips (no. 3), contenues dans le rapport antérieur de la sous-commission (A. McKellar, Président, r952), gardent toute leur actualité, de même d'ailleurs que la plupart des suggestions formulées par P. Swings, dans son rapport à la Joint Commission for Spectroscopy (J.Opt. Soc. Amer. 4I, I53, 195I).

I. Descriptions de spectres moléculaires. De nouvelles mesures à haute résolution de spectres simples de molécules cosmiquement abondantes s'imposent encore (Bidelman, Fujita, Herbig, Jenkins, Nassau, Nevin, Phillips, Swings), notamment:

$\mathrm{CN}$ (surtout le système rouge, bandes $2-0,3-0,4-0$ );

$\mathrm{CH}$ (surtout les transitions de grands quantiques de vibration);

$\mathrm{ZrO}$ (surtout le système $\mathrm{A}$ );

TiO (système $a \rightarrow x$ );

$\mathrm{FeO}$;

$\mathrm{N}_{2}$ (notamment système de Vegard-Kaplan dans la région 4000-5200, G. Kvifte).

En particulier, le domaine infrarouge proche (surtout de $\lambda$ 7000 à $\lambda 9000$ ) devrait être couvert, p. ex. pour les systèmes de TiO ( $\lambda$, intensités et profils). On doit aussi étudier les spectres moléculaires dans l'ultraviolet lointain $(\lambda<2000)$, notamment en vue des identifications solaires (G. P. Kuiper, C. M. Sitterly). Il faut insister, comme le fait Mme Sitterly, sur la nécessité de tables moléculaires précises pour la discussion critique de la présence ou absence de molécules dans les spectres du soleil et des étoiles. D'autre part, Nevin exprime le vœu qu'une compilation des raies de taches solaires soit publiée, afin que les spectroscopistes de laboratoire puissent essayer d'identifier leurs bandes de 
laboratoire dans les taches. Une coopération étroite s'impose certainement entre spectroscopistes solaires, comme Mme Sitterly, et de laboratoire, comme Nevin.

2. Il faut d'ailleurs remarquer, comme le fait Nevin, que les mesures de maints spectres de laboratoire sont très imprécises. Nevin suggère la mesure interférométrique de quelques raies dans différentes bandes.

3. L'obtention de spectres d'ions moléculaires, positifs et négatifs s'impose de plus en plus (L. Brewer).

4. Il est, sans doute, inutile d'insister encore sur la nécessité d'obtenir: (I) de meilleures constantes (vibration et rotation) et, surtout, de meilleures valeurs de l'énergie de dissociation pour des molécules astronomiques telles que $\mathrm{TiO}, \mathrm{ZrO}, \mathrm{VO}$; (2) les potentiels d'ionisation de molécules cosmiquement abondantes (par spectroscopie ultraviolette lointaine); (3) des mesures des probabilités de transition; (4) des expressions des fonctions d'excitation pour des molécules comme $\mathrm{H}_{2}, \mathrm{~N}_{2}, \mathrm{O}_{2}, \mathrm{NO}$, $\mathrm{CO}$, etc. (par croisement de jets moléculaires étroits et de jets électroniques ou ioniques homogènes, $\mathrm{B}$. Rosen).

5. La sous-commission croit avoir continué à remplir un rôle utile, particulièrement en supportant le projet d'Atlas de spectres moléculaires. Il est suggéré que son activité soit prolongée pendant le prochain triennat ou, tout au moins, jusqu'à ce que l'Atlas soit terminé. Il est également demandé instamment que toute l'aide possible soit accordée au Père Junkes dans son travail éminemment utile.

\section{P. SwINGS \\ Président de la Sous-commission}

\section{Addenda to Draft Report}

M. Hack has started observation of metallic-line stars at Merate; a dispersion of $35 \AA / \mathrm{mm}$. is used in comparing $\xi$ Cep, $\theta$ Cep, $\zeta$ Lyr A with $\iota$ Peg, 4 I Cyg, $\beta$ Cas, $\delta$ Cas. She finds similarity to $\tau \mathrm{U} \mathrm{Ma}$ in turbulence, low pressure and gravity, and abundance deficiencies for $\mathrm{Ca}, \mathrm{Zr}, \mathrm{Ti}$, Sc. The metallic-line star $\zeta$ Lyr A was studied by Hardorp, who also attempted to construct model atmospheres. One had normal stratification except for variable abundance of metals, the other had a super-giant structure in the outer regions, with deficiencies of individual elements.

M. Hack has studied the A 3 Ia super-giant, 6 Cas; she finds low $\mathrm{T}_{\text {exc }} \sim 7500^{\circ} \mathrm{K}$, turbulence of $\mathrm{I} 6 \mathrm{~km}$. $/ \mathrm{sec}$. The surface gravity $\log g-\mathrm{I}$ and $T-\mathrm{I} 2,600^{\circ} \mathrm{K}$. from the $\mathrm{H}$ lines.

A systematic study of Be stars has been undertaken at Haute Provence by Mme Herman, who is observing at least once a year the stars in the Mount Wilson Catalogue, brighter than $7^{\mathrm{m}}$ and north of $-20^{\circ}$. Stars $\mathrm{Bo}-\mathrm{B} 9$ have been added recently to this programme, and new emission-line objects found: HD 534I6, I4I569, I62732, I755II.

Attempts to place visual classification criteria onto a quantitative basis have been initiated at Hamburg-Bergedorf. Relative intensities of features have been measured in pairs of strong and weak-line stars; studies have been made of KO III stars for a possible third classification parameter and the $\lambda 4216$ band of $\mathrm{CN}$ measured. In addition a $60 \AA / \mathrm{mm}$. spectrophotometric survey of standard MK types has been completed.

The system of $\zeta$ Aur at the I950 eclipse was studied at Hamburg-Bergedorf, and of 32 Cyg in the r949 and I952 eclipses. The spectra of the components of $\alpha$ Aur were reconstructed from the blended curves at various phases.

At Canberra a three-prism spectrograph, $36 \AA \mathrm{mm}$. was brought into service on the 30 in. reflector and will be transferred to the 50 in. A two-prism spectrograph of lower dispersion is planned for the Newtonian focus of the 74 in. Miss M. L. Woods, using spectra obtained by W. B. Rinner, classified five hundred bright southern stars on the MKK system. The stars of the current radial velocity programme will be classified on the MK system as plates are obtained.

Stewart at Mount Wilson and Palomar has identified lines of TiII in HD 37058 , a slightly sub-luminous member of the Orion aggregate. A less sub-luminous star, HD I 35485 has been analysed and shown to have an abundance of helium about three times that of his comparison stars. 


\section{Report of first Meeting. 3I August r955}

President: Dr J. L. Greenstein.

Secretary: Dr G. H. Herbig.

The meeting opened with several announcements regarding activities that fall in the provinces of sub-commissions of Commission 29.

I. Reference was made to the very extensive catalogue of nova spectrograms now in preparation by Vorontsov-Velyaminov. Many observatories have co-operated by supplying lists of plates in their files, together with pertinent data, but the present status of this project was not known to the Chairman. It was announced that VorontsovVelyaminov had asked to be relieved of the chairmanship of the Sub-commission on the Spectra of Novae, and that, in accordance with a proposal made at the General Assembly in Rome, the Executive Committee had decided to discontinue that sub-commission $(29 c)$ and transfer its activities to the Sub-commission on the Spectra of Variable Stars $(29 b)$. With regard to Vorontsov-Velyaminov's recommendations for future observational work on novae (p. 407), Commission 29 formally endorsed these proposals.

2. Proposals by Bidelman and Mrs Payne Gaposchkin that the Sub-commission on the Spectra of Variable Stars act as a clearing-house for certain information on current work in that field were discussed more completely during the joint meeting of Commissions 27 and 29 (see below).

3. Swings reported to the Commission on the activities of a new physical laboratory at the University of the Saar. Its programme emphasizes the investigation of molecular spectra of astrophysical interest, Greenstein expressed the Commission's interest in, and admiration for, such work.

Swings also drew the attention of the Commission to the new high-resolution atlas of the infra-red solar spectrum by Migeotte and his collaborators, and to the atlas of cometary spectra, both prepared at Liège. Illustrations from both atlases were exhibited.

The Commission then discussed the proposals put forward for its consideration (pp. 40r-403).

I. Information centre for stellar spectra. It was emphasized in the discussion that for such a centre to be fully useful, it must have access to plate files and unpublished material. Lacking these desiderata, which would be most difficult to arrange, it was felt that such a centre could supply only the information which the working astronomer is accustomed to obtain for himself from the usual bibliographical sources. No strong sentiment was expressed during the meeting for the organization of such an information centre, and consequently the Commission took no action. It did, however, encourage the continuation of the existing card catalogue of spectroscopic information prepared by Keenan at the Perkins Observatory.

2. 'Information centre on composite spectra. Hynek's proposal to organize such a centre at the Perkins Observatory was endorsed; the Commission recommended, furthermore, that those working in this field co-operate with Hynek so that the information at the disposal of the centre be as complete as possible. The further proposal was made during the discussion that the importance of systematic multicolour observation of composite systems be urged upon photo-electric observers. It was decided that the attention of Commissions 25 and 27 should be drawn to the importance of this work, and that the value of radial velocity work on composite objects be emphasized to Commission 30 .

3. Recommendation on the spectra of comets. The matter was regarded as being more appropriate to Commission $\mathrm{I} 5$, and consequently no action was taken.

4. Recommendation for increased effort. Swings spoke of the desirability of extending our detailed knowledge of stellar spectra to the region of $\lambda$ 5000, and especially of $\lambda 7000$. Greenstein and Underhill agreed, and mentioned recent improvements in photographic emulsions that should encourage work in the visual and infra-red regions.

5. Revision of commission structure was not discussed. 
A second series of proposals (pp. 402403 ) was also considered by the Commission.

I. Current lists of objects under spectroscopic observation. No substantial support for such a 'news letter' was expressed.

2. Lists of unpublished spectra of variable stars. Discussion of this topic was postponed until the joint meeting of Commission 27 and 29.

3. A catalogue of known metallic-line stars. W. W. Morgan urged caution in this field, because of the lack of general agreement on criteria. For example, unless care and conservatism are exercised, there is danger that peculiar A-type stars might be confused with the metallic-line objects. Considerable discussion followed from which it was evident that work on the metallic-line stars was under way at a number of institutions. In view of the extensive current activity, the sentiment of the Commission was that the time is not yet ripe for a definitive catalogue of metallic-line stars.

4. List of standard spectral types for southern observers. Morgan expressed his interest in making the MK system available to southern observatories, and offered to set up standards as far south as $\delta=-20^{\circ}$, referred to his northern primary standards. For the information of Commission 29, Thackeray reported on the activity of the informal subcommission that at the last General Assembly was charged with consideration of this matter. He emphasized that this informal group has not been concerned with the question of which system of spectral classification is to be preferred, but rather whether every system is adequately defined by standards accessible from both hemispheres. $\mathrm{He}$ thanked Joy, Greenstein, and Morgan for their co-operation in providing new data. A number of extensive lists of spectral types of southern stars, both published and in preparation, were discussed. It was concluded that, since the present composition of Thackeray's informal sub-commission is satisfactory, and its work is not finished, both the sub-commission and its present membership should be continued for another three years.

5. A spectrophotometric atlas of high-dispersion stellar spectra. Mrs Payne Gaposchkin spoke strongly in favour of such an atlas, but emphasized that at least fifty stars would have to be included in order to display normal representatives of all spectral classes and luminosities. Schwarzschild agreed as to the major importance of such an atlas, and felt that it would be put to great use in many fields, since the amount of relatively accurate spectrophotometric data available is quite small. Greenstein, speaking as an active worker in this field, pointed out that to make full use of the information available on modern high-dispersion stellar spectrograms, each star would require a volume comparable in size to the Utrecht Atlas. Miss Underhill commented that, since two or more spectrograms should be combined in the final tracing, the amount of labour required would be large.

Swings agreed in principle to the desirability of such an atlas, but felt that in practice it would be quite impossible to produce the equivalent of fifty Utrecht Atlases. $\mathrm{He}$ inquired if, since the number of theoretical astrophysicists likely to make use of such a complete atlas would be small, would not the purposes of such a project be served equally well if the institutions capable of furnishing such data were willing to supply plates, limited to a single star and a restricted wave-length region, upon request? As the result of considerable iliscussion, it was finally decided to set up an informal sub-commission (composed of Greenstein, de Jager, and Unsöld) to discuss all aspects of the atlas problem, and to report its conclusions back to Commission 29 .

6. Completion of the atlas of molecular spectra. This matter is in the hands of Subcommission $29 c$.

7. A new edition of the Yerkes Atlas of Stellar Spectra on an enlarged scale. Morgan stated that work on a second edition of the Yerkes Atlas was begun six to eight years ago, but work ceased for lack of financial support. He is now preparing a monograph on spectral classification, but it differs from the Atlas in that half-tone reproductions of spectrograms will be employed rather than photographic prints. He pointed out that the primary MK standards are given in $A p . J .117,73$, r953. Additional MK types for southern stars of early type appear in $A p . J .$, Suppl. no. 14, 1955, but there is a slight 
question if this second list is entirely homogeneous with the first. Morgan offered to supply additional standards, as far as he is able, to astronomers engaged in programmes for which published standards are inadequate. The Chairman expressed the great appreciation of the Commission to Morgan and his collaborators for their work in preparing the original Yerkes Atlas.

8. The Classification of $G_{5}-K_{3}$ Giants was discussed by Keenan in an Appendix to the Report of Commission 29 (p. 404-505). Following a discussion of this problem, the Chairman proposed that $(a)$ the attention of workers in the field be drawn to Keenan's proposals; $(b)$ that Keenan be encouraged to continue his work on the systematization of spectral classification in this region of the spectrum-luminosity diagram, and that he be urged to add more standard stars for $C N$ intensities; and (c) that Commission 29 recommend that Keenan's notation be employed tentatively, pending further developments. The Commission concurred in these proposals.

\section{Report of second Meeting. 3 September r955}

President: Dr J. L. Greenstein.

Secretary: Dr G. H. Herbig.

The second session of Commission 29 was devoted to the presentation of short scientific communications. The speakers and subjects were as follows:

I. B. E. Pagel (Radcliffe): A search for southern $\beta$ Canis Majoris variables.

2. A. B. Underhill (Victoria): Recent work on 48 Librae.

3. W. P. Bidelman (Lick): The spectra of the components of visual double stars.

4. K. O. Wright (Victoria): Recent work on $\epsilon$ Eurigae.

5. N. G. Roman (Yerkes): Comments on the spectra of high-velocity stars.

6. L. Gratton (La Plata): Observations of $\mathrm{H}$ and $\mathrm{K}$ emission in the Cepheid, $l$ Carinae.

7. H. F. Weaver (Berkeley): An interpretation of the structure of the emission lines in Nova Aquilae I9I8.

8. E. M. Burbidge (Cambridge): The production of over-abundances of the heavy elements in magnetic variables.

\section{Report of joint Meeting of Commissions 27 (Variable Stars) and 29 (Stellar Spectra).}

President: Dr J. L. Greenstein. 3 September I955

Secretary: Dr G. H. Herbig.

The joint meeting opened with the Chairman calling attention to those portions of the report of Commission 27, prepared by Prof. Kukarkin, dealing with problems that require the joint attention of both variable star observers and spectroscopic workers. The purpose of this joint meeting was to consider projects that clearly lie near the boundary between Commissions 27 and 29. A number of proposals of this character were put forward.

I. Prof. Swings drew attention to the very great need for the determination of light and colour curves of carbon (type $R$ and $N$ ) variables at times that spectroscopic observations are being made. His group at Liège is studying the spectra of a number of the brighter stars of this kind (such as $\mathrm{U}$ Hya and Y CVn), but the interpretation of the results is handicapped by lack of photometric data. Prof. Swings stated that spectroscopic work on these stars will continue (at Asiago) for the next three to four years, and he hopes that photometric observers in a position to co-operate in this programme will communicate with him at Liège for the list of stars to be observed, and other details.

2. Prof. Swings pointed out also the need for photo-electric studies of possible changes in light and colour among the Of stars. He believed that the variations will probably 
be small in amount but may be either slow (so that only a few observations per year would be required) or perhaps very rapid (so that nearly continuous photometric coverage in the course of a night would be indicated). Dr Gratton concurred in this recommendation, and stressed the desirability of concurrent spectroscopic and photometric observations.

3. The need for photometric observations of symbiotic stars in the ultra-violet was also pointed out by Professor Swings. He stated that the early-type components of such systems as Boss I985 ( $=\mathrm{HR} 2902)$ often show major spectroscopic variations in the ultra-violet, while at the same time the late-type stars, which dominate in the photographic and visual regions, do not change. Prof. Swings expects that such changes will proceed rather slowly, so that observations over some years are indicated.

4. Prof. Swings also stressed the urgent need for narrow-band photometry of variable stars. As an example, he cited the interesting data that would ensue from an isolation of features such as $\mathrm{H} \alpha$, the $\mathrm{NI}$ and $\mathrm{N}_{2}$ lines of [O III], and a section of TiO bands and continuum, in symbiotic variables.

5. Miss Underhill drew the attention of photo-electric observers to the desirability of systematic observations of some of the brighter shell stars over a period of years. In an object such as 48 Librae, which exhibits recurrent periods of spectroscopic activity, accurate photometric observations might contribute in a major way to the interpretation. At the present time, essentially no information of this kind is available.

At the close of these proposals for co-operative or increased effort by photometric and spectroscopic workers, the recommendations were formally endorsed by Commissions 27 and 29.

During the meeting of Commission 29, Mrs Payne Gaposchkin had made a suggestion directed to spectroscopic investigators of variable stars. She proposed that spectroscopic observers inform her, as Chairman of the Sub-commission on the Spectra of Variable Stars $(29 b)$, of the nature of any extensive programmes in which they were engaged. She could then employ this information so as to avoid needless duplication of effort between astronomers, and to encourage co-operative programmes.

At the joint meeting of Commissions 27 and 29, Dr Bidelman (acting for Mrs Payne Gaposchkin in her absence) presented a more specific suggestion, as follows. It was proposed that, on the one hand, members of Commission 29 desiring photometric information on certain variable stars, as well as, on the other, members of Commissions 27 and 42 that required spectroscopic data, should send such requests to the Chairman of Sub-commission $29 b$. The Chairman would, at regular intervals, circulate this information to those members of the three Commissions who desire to receive it. Interested astronomers could then communicate directly with one another. Mrs Payne Gaposchkin having stated her willingness to undertake this activity, the proposal was approved by Commissions 27 and 29. However, no desire was expressed for any effort to collect and circulate detailed information on current activity in the field of variable star spectra. During the discussion, Dr J. E. Merrill pointed out that the Princeton-Cook card catalogue and the Wood Finding List are sources of information on current work in the field of eclipsing binaries.

Dr Herbig called attention to a major problem faced by spectroscopic observers of faint variable stars: namely, that for lack of a chart of the immediate vicinity of the variable, many interesting objects cannot be located. He made two proposals: $(a)$ that these Commissions express their concern at this impediment to progress, and encourage the observatories responsible for such uncharted discoveries in the past to publish charts. This would be a long-term project, so $(b)$. for the purpose of permitting work on stars of current interest, Dr Herbig proposed that a canvass be made of all astronomers in Commissions 27 and 29 who may be faced with such identification difficulties. They would be asked for the names of specific variable stars which they propose to study, or have attempted to study, but for which identification is a problem. Probably a list of such stars would be of quite moderate length. Then, with the authorization of Commissions 27 and 29, the appropriate observatories could be approached in an effort to secure identification charts for stars in this limited list. In the discussion that followed, the 
Chairman commented that some observatories, among which Sonneberg was an outstanding example, made an intensive effort to publish such charts with the discovery announcement. Dr Hoffmeister commented that, even so, the Sonneberg Observatory had not furnished charts for all its discoveries, but he offered to supply such missing charts on request. Commissions 27 and 29 approved Dr Herbig's proposals, and appointed him to proceed with the project described in $(b)$.

The Chairman then inquired if there was any feeling that certain classes of variable stars were being seriously neglected by either spectroscopic or photometric observers. Both he and Dr Nassau reiterated Prof. Kukarkin's remark that the study of physical variables by photo-electric observers should be extended, and Prof. Swings commented that the slowly-changing variables particularly are in need of attention. Dr Fracastoro and Dr Bidelman noted that certain long-period eclipsing binaries such as $\mathrm{V}_{3} 8 \mathrm{I}$ Sco, $v$ Sgr, and $\mu$ Sgr deserve more study, the former spectroscopically, the other photoelectrically. Dr Huffner called attention to the fact that certain variables with periods near an integral multiple of one day were difficult to study from a single observatory, but were especially suitable objects for international co-operation. Dr Hopmann stated that, because of obvious difficulties, certain variables that were the fainter components of double stars (such as i Boo B) had not received adequate attention. He noted that this was a field where the visual observer could still contribute. Prof. Swings remarked that the $\mathrm{R} \mathrm{CrB}$ variables well deserved photometric attention.

Report of Meeting of Sub-commission 29c on Molecular Bands in Stellar Spectra.

President: Prof. P. Swings. 2 September 1955

Secretary: Dr John G. Phillips.

Dr D. J. O'Connell, Director of the Vatican Observatory, in the absence of Fr Junkes, presented the following complementary report on the status of the Atlas of Molecular Spectra:

$$
\text { I. THE PLAN }
$$

The title of this volume of the Atlas has been changed to:

\section{Molecular Spectra of Metallic Oxides}

on account of the reasons indicated in the Draft Report, especially in order to adapt the title to the real contents of the volume, and, at the same time, because we do not intend to bind ourselves to further volumes.

We had the intention of representing all metallic oxides; but some of the spectra could not be excited, or at least not properly, with the means at our disposal. To avoid further delay in the publication of this volume, those elements have been passed over. The same holds for oxides with bands only in the UV, as e.g. Ge, Si, as of less astrophysical interest.

\section{The Present State of the Work}

(a) The spectra: All spectra have been taken. In addition to the spectra previously made by Fr Gatterer (oxides of $\mathrm{Ba}, \mathrm{Ca}, \mathrm{Ce}, \mathrm{Cr}, \mathrm{Dy}, \mathrm{La}, \mathrm{Nd}, \mathrm{Pr}, \mathrm{Sm}, \mathrm{Sr}, \mathrm{Ti}, \mathrm{V}, \mathrm{Y}$ and C) the following band spectra have been obtained:

I. With the Carbon Flame: oxides of Er, Fe, Gd, Ho, Lu, Mn, Sc, Tb.

2. With the Arc: oxides of $\mathrm{Al}, \mathrm{B}, \mathrm{Be}, \mathrm{Cu}, \mathrm{Eu}, \mathrm{Mg}, \mathrm{Mo}, \mathrm{Nb}, \mathrm{Ta}, \mathrm{Th}, \mathrm{W}, \mathrm{Yb}, \mathrm{Zr}$.

For these latter spectra those parts of the arc and the aureola were used in which the bands appear better and less disturbed by atomic lines. Sometimes very satisfactory bands were obtained by enlarging and stabilizing the arc flame with a weak magnetic field. 
(b) The measurements: A great deal of the measurements are completed. The bandheads in the literature were identified. Some new bands were measured and analysed by Dr Rosen and his colleagues at the Liège Astrophysical Institute. The work on a few spectra is not yet completed, as e.g. ThO.

(c) The enlargements of the originals have all been made and tentatively put together on about thirty-two plates of size $30 \times 40 \mathrm{~cm}$., each containing five rows of spectra, as already displayed by Fr Gatterer. The spectra are arranged in alphabetical order according to their chemical symbols.

(d) The text will contain a description of the experimental conditions, a catalogue of the band-heads and some brief remarks, and will be compiled in collaboration with Dr Rosen.

\section{The Prospects}

If there are no unforeseen difficulties in the preparation of the definitive plates for the photographic reproduction and the text, it is hoped that the volume can be presented at the seventh International Astrophysical Symposium at Liège, July I956.

(Signed) Joseph Junkes

Castel Gandolfo, I7 August 1955

The sub-commission expressed its profound satisfaction that the Atlas of Molecular Spectra of Metallic Oxides was so close to completion, and wished to congratulate the Vatican Observatory on the excellent manner with which it had carried out so monumental a task. Dr Phillips expressed his view that the value of the Atlas would be even further enhanced for astronomers if a supplementary Atlas could be prepared, to include the spectra of astrophysically important diatomic hydrides, nitrides, and homonuclear molecules, e.g. $\mathrm{CH}, \mathrm{OH}, \mathrm{CN}, \mathrm{NH}, \mathrm{C}_{2}$. Dr Swings suggested that, in view of the fact that many of these additional spectra require the use of laboratory sources not readily available at the Vatican Observatory, they consider the enlistment of the co-operation of other spectroscopy laboratories, in providing spectrograms suitable for inclusion in such an Atlas. It was decided to incorporate these suggestions in a Resolution to be presented to the I.A.U.

According to the Vatican Observatory, a portion of the funds granted by the I.A.U. for the production of the Atlas will remain unexpended after publication. It was suggested by Dr Swings, and approved by the sub-commission, that the Finance Committee of the I.A.U. be approached for authorization to utilize this unexpended balance to provide as many free copies as possible to interested astronomers and physicists. 